Cipango Cahiers d'études japonaises

$21 \mid 2014$

Nouveaux regards sur les arts de la scène japonais II

\title{
Religion et identité villageoise dans les communautés de chrétiens cachés et catholiques de Kyūshū (XIX ${ }^{\mathrm{e}}$ siècle)
}

Religion and Village Identity in the Hidden Christian/Catholic communities of Kyūshū (19th century)

\section{Martin Nogueira Ramos}

\section{(2) OpenEdition}

\section{Journals}

Édition électronique

URL : https://journals.openedition.org/cipango/2300

DOI : $10.4000 /$ cipango. 2300

ISSN : 2260-7706

Éditeur

INALCO

Édition imprimée

Date de publication : 31 décembre 2014

ISSN : 1164-5857

\section{Référence électronique}

Martin Nogueira Ramos, "Religion et identité villageoise dans les communautés de chrétiens cachés et catholiques de Kyūshū (xıx e siècle) », Cipango [En ligne], 21 | 2014, mis en ligne le 26 septembre 2016, consulté le 30 juin 2021. URL : http://journals.openedition.org/cipango/2300 ; DOI : https:// doi.org/10.4000/cipango.2300

Cipango est mis à disposition selon les termes de la Licence Creative Commons Attribution - Pas d'Utilisation Commerciale 4.0 International. 


\title{
Religion et identité villageoise dans les communautés de chrétiens cachés et catholiques de Kyūshū (XIX ${ }^{\mathrm{e}}$ siècle)
}

\author{
Religion and Village Identity in the Hidden Christian/ \\ Catholic communities of Kyüshü (19th century)
}

Martin Nogueira Ramos

CRCAO, université Paris Diderot

\section{Chrétiens cachés et catholiques de Kyūshū : problème de définition}

Deux thématiques de l'histoire du catholicisme japonais fascinent depuis longtemps les chercheurs : la première évangélisation du pays, appelée par certains le « siècle chrétien » du Japon (XVI ${ }^{\mathrm{e}}$-XVII ${ }^{\mathrm{e}}$ siècles), et l'existence de communautés de « chrétiens cachés » qui pratiquent une religion syncrétique mélangeant éléments catholiques, bouddhiques et shintô. Ces chrétiens cachés, qui se concentrent dans les parties nord et nord-ouest de l'île de Kyūshū, sont des descendants de catholiques qui ont réussi à traverser la longue période de proscription de leur religion (1614-1873) ${ }^{1}$. Ils ont développé au fil du temps un christianisme métissé, affichant

1. Pour une présentation géographique des communautés de chrétiens cachés à la fin de l'époque d'Edo et actuellement, voir MiYAZAKI Kentarō 宮崎賢太郎, Kakure kirishitan no shinkō sekai カクレキリシタンの信仰世界 (L'univers spirituel des chrétiens cachés), Tōkyō, Tōkyō daigaku shuppankai 東京大学出版会, 1996, p. 37-45. 


\section{CIPANGO}

262 Cahiers d'études japonaises n² 21

un respect formel de l'autorité des temples et sanctuaires shintô-bouddhiques. En mars 1865, une partie de ces groupes de chrétiens cachés prend contact avec les prêtres des Missions étrangères de Paris (MEP). Ces groupes se scindent alors entre ceux qui prônent la conversion au catholicisme sous sa forme nouvellement réintroduite et ceux qui la rejettent ${ }^{2}$. À en croire les missionnaires, il y aurait eu environ 50000 chrétiens cachés et catholiques vers $1880^{3}$.

Les spécialistes japonais désignent ces groupes par différents vocables. Kakure kirishitan 隠れキリシタン ou senpukukirishitan 潜伏キリシタン sont les plus fréquents. Ces deux termes peuvent se traduire par « chrétiens cachés », « crypto-chrétiens », voire « chrétiens clandestins » pour le second. L'anthropologue Miyazaki Kentarō 宮崎賢太郎, spécialiste du crypto-christianisme, propose de distinguer les chrétiens cachés de l'époque d'Edo, qui devaient par nécessité cacher leur religion, de ceux des époques postérieures, qui pratiquent leur religion secrètement non pas par crainte de représailles, mais pour respecter la tradition rituelle léguée par leurs parents et ancêtres. Il appelle les premiers senpuku kirishitan, et les seconds kakure kirishitan ${ }^{4}$. Il est assez difficile de rendre cette distinction linguistique en français. Dans cet article, nous appelons « chrétiens cachés » les descendants de catholiques qui pratiquaient en secret avant et après 1865, et « catholiques » ceux qui ont accepté l'autorité de l'Église après cette date.

Ces questions terminologiques doivent être affinées. Nous avons montré dans un autre article que quatre réseaux crypto-chrétiens coexistaient au XIX ${ }^{\mathrm{e}}$ siècle, et qu'il fallait donc relativiser l'idée selon laquelle ces communautés auraient été repliées sur elles-mêmes ${ }^{5}$. Le plus important de ces groupes s'étendait sur la

2. Il existe peu d'articles sur l'activité missionnaire catholique à l'époque Meiji. On peut se référer à Jean-Pierre Lehmann, "French Catholic Missionaries in Japan in the Bakumatsu and Early Meiji”, Modern Asian Studies, vol. 13, n 3, Cambridge, Cambridge University Press, 1979, p. 377-400.

3. AMEP (Archives des Missions étrangères de Paris), vol. 570, fol. 1784-1804, septembre 1879 .

4. MiYAZAKi Kentarō 宮崎賢太郎, op. cit., 1996, p. 30-31.

5. Martin Nogueira Ramos, «Bakumatsu-Meiji shoki no kirishitan minshū shakai no chiiki-teki kōzō ni tsuite no ichikōsatsu 幕末 明治初期のキリシタン民衆社 会の地域的構造についての一考察 (Réflexion sur l'organisation territoriale des communautés crypto-chrétiennes à l'époque du bakumatsu et au début de l'époque Meiji), Nihonshi kōkyū 日本史放究, no 36, Tōkyō, Nihonshi kōkyūkai日本史放究会, 2012, p. 23-43. 
pointe nord-ouest de Kyūshū. Nous l'avons appelé « groupe Sotome-Urakami ». Sotome 外海 est une région du fief d'Ōmura 大村, située au nord de Nagasaki, qui abritait plusieurs villages crypto-chrétiens. Urakami 浦上 est un gros village qui aujourd' hui fait partie intégrante de cette ville. Vers le milieu du XVIII ${ }^{\mathrm{e}}$ siècle, des chrétiens cachés de Sotome et Urakami ont commencé à migrer : à l'ouest vers l'archipel Gotō 五島, au sud vers la péninsule de Nagasaki et au nord vers Hirado 平戸. Un siècle plus tard, les descendants de migrants continuaient d'entretenir des liens avec les villages de leurs ancêtres. Les trois autres réseaux sont moins étendus géographiquement. On sait, grâce aux sources missionnaires, que plusieurs villages de chrétiens cachés - au moins quatre - de l'ouest de l'archipel d'Amakusa 天草 entretenaient des relations. À l'intérieur des terres, dans l'actuel département de Fukuoka, plusieurs communautés étaient actives dans le village d'Imamura 今村 et dans les alentours. Enfin, des villages de l'île d'Ikitsuki 生月 et de la bordure ouest de l'île de Hirado appartenaient à un même réseau crypto-chrétien. Cette étude concerne essentiellement les groupes Sotome-Urakami et Imamura. Ceux-ci ont massivement choisi de rejoindre le catholicisme à partir de 1865 . Nous disposons à leur sujet d'une importante documentation française et japonaise.

La quasi-totalité des chrétiens cachés était des villageois et avaient donc le statut de hyakushō 百姓 (littéralement les «cent-noms »). Les activités qu'ils exerçaient ne différaient en rien de celles du reste de la population rurale. Dans les îles et sur la côte, la culture des champs et des rizières n'était en général pas suffisante pour assurer la subsistance des populations. Beaucoup devaient aussi s'adonner à la pêche. À proximité de Nagasaki, en particulier à Urakami, une part des revenus villageois provenait de l'artisanat et du commerce. À Imamura, les crypto-chrétiens étaient essentiellement des laboureurs ${ }^{6}$.

\section{Quelles sources pour l'étude des villages de catholiques et de chrétiens cachés?}

Notre étude se focalise sur le XIX ${ }^{\mathrm{e}}$ siècle car l'état des sources nous empêche de suivre l'évolution précise de ces groupes tout au long de l'époque d'Edo. À par-

6. Sur les activités économiques des chrétiens cachés, nous renvoyons à nos travaux : Martin Nogueira Ramos, Crypto-christianisme et catholicisme dans la société villageoise japonaise $\left(X V I I^{e}-X I X^{e}\right)$, thèse de doctorat de l'université Paris Diderot, sous la direction d'Annick Horiuchi, $2014 b$. 
tir de 1614 , le catholicisme est interdit. Outre le recours fréquent à la répression physique, le bakufu impose progressivement à ses sujets des obligations à caractère religieux, notamment l'inscription dans un «temple-paroisse » (danna dera 檀 那寺) ou le piétinement d'images chrétiennes représentant le Christ ou la Vierge (ebumi 絵踏 $)^{7}$. Les communautés de descendants de catholiques adhèrent au nouveau système et, officiellement, vers la fin du XVII ${ }^{\mathrm{e}}$ siècle, le catholicisme est considéré comme éradiqué ${ }^{8}$.

Cette disette documentaire est en partie comblée par une série d'enquêtes menées à la fin de l'époque d'Edo par le shogunat et différents fiefs sur les mœurs religieuses de certains villages ${ }^{9}$. Le contexte social et économique fort instable incite les gouvernants à surveiller de près les roturiers. Par exemple, avant 1865, le village d'Urakami est à trois reprises la cible du préfet de Nagasaki (1790$1796,1842,1856-1860)^{10}$. Au début du $\mathrm{XIX}^{\mathrm{e}}$ siècle, près de cinq mille paysans de quatre villages de l'ouest d'Amakusa sont également inspectés par les guerriers du fief de Shimabara ${ }^{11}$. Officiellement, les villageois concernés ne sont pas considérés comme des chrétiens par les autorités, mais comme des sujets aux mœurs

7. Sur le développement du système religieux au début de l'époque prémoderne, voir TAMAmuro Fumio 圭室文雄, Nihon bukkyo-shi - Kinsei 日本仏教史一近世 (Histoire du bouddhisme japonais : l'époque prémoderne), Tōkyō, Yoshikawa kōbunkan 吉川弘 文館, 1987, p. 61-81.

8. Les autorités procèdent à des arrestations de catholiques jusqu'à la fin du XVII ${ }^{\mathrm{e}}$ siècle. On trouve plusieurs articles factuels sur ces arrestations dans Hubert CiesLIK (dir.), Kirishitan キリシタン, Tōkyō, Tōkyōdō shuppan 東京堂出版, 1999, p. 258-264.

9. Au sujet de ces enquêtes, on peut consulter ŌHAshi Yukihiro 大橋幸泰, 《Mura shakai no shūkyō jōsei to itan-teki shūkyō katsudō » 村社会の宗教情勢と異端的 宗教活動 (La situation religieuse des sociétés villageoises et les mouvements religieux hétérodoxes), Rekishi hyōron 歴史評論, nº 743, Tōkyō, Azekura shobō 校倉書房, 2012, p. 66-80.

10. Ces trois enquêtes sont appelées dans l'historiographie japonaise : Urakami ichiban kuzure 浦上一番崩れ, Urakami niban kuzure 浦上二番崩れ et Urakami sanban kuzure 浦上三番崩れ. Kuzure 崩れ signifie le démantèlement, l'affaissement d'une structure.

11. Le déroulement des enquêtes d'Urakami et Amakusa est présenté dans KATAOKA Yakichi 片岡弥吉, Nihon kirishitan junkyō-shi 日本キリシタン殉教史 (Histoire des martyrs catholiques japonais), Tōkyō, Jiji tsūshinsha 時事通信社, 1979, p. 542-550. 
religieuses différentes, voire étranges ${ }^{12}$. En 1868 enfin, le fief de Kurume 久留 米 mène des investigations sur Imamura, village où quelques habitants se sont convertis au catholicisme, alors que l'écrasante majorité continue de pratiquer dans la clandestinité. Les documents relatifs à cette affaire nous offrent à la fois un témoignage sur les motivations des convertis et sur la pratique religieuse des chrétiens cachés ${ }^{13}$.

Le retour du clergé catholique et le mouvement de conversion qui touche les groupes de chrétiens cachés à partir de 1865 nous donnent accès à d'autres sources, en particulier missionnaires. Ces documents, encore largement inexploités, sont conservés pour la plupart aux archives des Missions étrangères, rue du Bac à Paris ${ }^{14}$. En outre, le mouvement de conversion a fait resurgir la question de la liberté du culte chrétien au Japon. Officiellement, le catholicisme était toujours considéré comme illicite en 1865 . Le régime agonisant des Tokugawa essaie d'arrêter le mouvement de conversion, mais c'est le nouveau gouvernement de Meiji qui s'empare réellement de la question catholique pour affermir les bases idéologiques du régime. Près de 3000 catholiques du village d'Urakami sont ainsi envoyés en exil entre 1868 et $1873^{15}$. Dans d'autres régions du nord de Kyūshū, des convertis subissent différentes formes de répression ${ }^{16}$.

Au niveau documentaire, ces épisodes du catholicisme japonais sont assez bien renseignés. Après 1873, et le début de la tolérance tacite du catholicisme, les

12. ŌHASHI Yukihiro 大橋幸泰, Kirishitan minshū-shi no kenkyū キリシタン民衆 史の研究 (Études sur l'histoire du christianisme populaire japonais), Tōkyō, Tōkyōdō shuppan 東京堂出版, 2001, p. 167-169.

13. Pour une brève présentation de l'histoire du village d'Imamura, voir Hubert CiEsLIK (dir.), op. cit., 1999, p. 304-305.

14. Le fonds des Missions étrangères de Paris a été présenté par Nakajima Akiko 中島 昭子, 《Pari gaikoku senkyō-kai shozō Nihon kankei shiryō no kenkyū »パリ外国宣 教会所蔵日本関係史料の研究 (Étude des documents des Missions étrangères de Paris relatifs au Japon), Kenkyū kirishitan-gaku 研究キリシタン学, $n^{\circ} 4$, Kirishitan-gaku kenkyū-kai キリシタン学研究会, 2001, p. 1-63.

15. Cet épisode de l'histoire du catholicisme japonais est appelé le Urakami yonban kuzure 浦上四番崩れ. Pour une présentation des faits, voir KATAOKa Yakichi 片岡 弥吉, Urakami yonban kuzure 浦上四番崩れ (Le quatrième démantèlement du village d'Urakami), Tōkyō, Chikuma shobō 筑摩書房, 1991.

16. Hubert Cieslik (dir.), op. cit., 1999, p. 295-296 ; 304-305 ; 306-307. 
enquêtes des autorités sur ces villages cessent. Cela ne signifie pas pour autant que les chrétiens aient joui d'une liberté totale. En effet, avant 1889, année de promulgation de la première Constitution moderne de l'archipel, la liberté de culte n'est pas encore garantie. Le statut juridique des catholiques, et plus généralement des chrétiens, reste flou, ce qui continue d'engendrer au niveau local des conflits entre les autorités et ces communautés ${ }^{17}$.

Après 1873, la plupart des documents disponibles sur la question sont d'origine missionnaire. Nous avons extrêmement peu de documents écrits par des chrétiens cachés et très peu sont produits par des convertis. Cependant, les chrétiens cachés ont transmis de génération en génération des documents manuscrits, à commencer par un ouvrage intitulé Tenchi hajimari no koto 天地始之事 (Le commencement du Ciel et de la Terre $)^{18}$, qui rassemble des traditions orales fortement teintées de croyances locales sur la création du monde, le Christ et la Vierge Marie ${ }^{19}$. L'ensemble de ces documents permet d'étudier la mentalité religieuse des chrétiens cachés et des catholiques du XIX ${ }^{\mathrm{e}}$ siècle.

17. Suzue Eiichi 鈴江英一 a recensé un certain nombre de conflits juridiques liés à la pratique du christianisme après 1873, dans Kirisuto-kyō kaikin izen - Kirishitan kinsei kōsatsu tekkyo no shiryō-ron キリス卜教解禁以前一切支丹禁制高札撤去の史料論 (Avant la levée de l'interdiction contre le christianisme : discussion à partir des sources sur la suppression des placards stipulant l'interdiction de cette religion), Tōkyō, Iwata shoin 岩田書院, 2001, p. 133-139.

18. Ce texte a fait l'objet de plusieurs éditions modernes en japonais. Celle de référence se trouve dans Hubert Cieslik, Doi Tadao 土井忠生, EBISAwa Arimichi 海老沢有 道, ŌTSUKA Mitsunobu 大塚光信, Kirishitan-sho haiya-sho キリシ夕ン書 排耶 書 (Textes catholiques, textes anticatholiques), Nihon shisō-shi taikei 日本思想史体系 (Anthologie de textes sur la pensée japonaise), vol. 25, Tōkyō, Iwata shoin 岩田書院, 1970, p. 381-409. Les passages du texte que nous citons proviennent de la traduction française élaborée par Géraldine Antille, Les Chrétiens cachés du Japon : traduction et commentaire des «Commencements du Ciel et de la Terre », Genève, Labor et Fides, 2007, p. 41-69. Il existe également une traduction anglaise du texte très utile pour son appareil critique : Christal Whelan, The Beginning of Heaven and Earth: The Sacred Book of Japan's Hidden Christians, Honolulu, University of Hawai'i Press, 1996. La date de rédaction du texte est inconnue. Le plus ancien manuscrit date de l'ère Bunsei (1818-1830).

19. Sur la structure et le contenu du Tenchi, voir KamiYa Takehiro 紙谷威広, Kirishitan no shinwa-teki sekai キリシタンの神話的世界 (L'univers mythologique des chrétiens cachés), Tōkyō, Tōkyōdō shuppan 東京堂出版, 1986. 


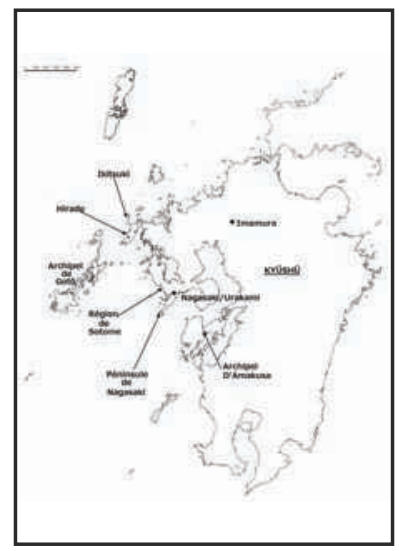

FIGURE 1.

Principales régions de Kyūshū abritant des populations crypto-chrétiennes ou catholiques au XIX ${ }^{\mathrm{e}}$ siècle. Source : Martin Nogueira Ramos

\section{Les chrétiens cachés, un exemple de communauté religieuse}

Le monde religieux des campagnes au XIX ${ }^{\mathrm{e}}$ siècle est extrêmement riche et complexe. Il est impossible de limiter l'identité religieuse d'un village, voire d'un individu, à une seule croyance. Officiellement, les seules obligations sont celles de l'inscription sur les registres d'un temple et de la participation des moines aux enterrements. Chaque village compte un ou plusieurs temples, ainsi que, le plus souvent, un sanctuaire dédié à une divinité tutélaire, appelée ujigami 氏神 ou ubusunagami 産土神. On trouve aussi un certain nombre de confréries, $k \bar{o}$ 講, centrées autour du culte de différentes divinités shintô-bouddhiques et affiliées à des lieux de pèlerinage particulier, le plus prisé étant le sanctuaire d'Ise. Un même villageois peut être membre de différentes confréries. À cela, il faut encore ajouter une foule de religieux, en général itinérants, qui gravitent autour de la société vil- 


\section{CIPANGO}

lageoise ${ }^{20}$. C'est aussi au XIX ${ }^{\mathrm{e}}$ siècle qu'apparaissent ce que l'historiographie japonaise appelle les « nouvelles religions ( shinshükyo 新宗教). Celles-ci expriment un désir de « renouveau du monde $\gg(\text { yonaosh } i \text { 世直し })^{21}$.

Comment se situent les chrétiens cachés et les catholiques par rapport à la société environnante et ce foisonnement religieux ? À travers l'exemple de ces villages du nord de Kyūshū, nous voudrions montrer en quoi le facteur religieux a pu grandement contribuer au façonnement d'une organisation sociale autonome et à l'élaboration d'une identité villageoise et communautaire propre. Si ces groupes ne sont pas forcément représentatifs de l'ensemble de la population, ils constituent une facette de la religiosité populaire du XIX ${ }^{\mathrm{e}}$ siècle. On peut, par exemple, rapprocher la pratique religieuse des chrétiens cachés d'autres mouvements tel l'amidisme clandestin (kakure nenbutsu 隠れ念仏). Les amidistes clandestins sont à l'origine des fidèles de l'École véritable de la Terre pure (Jōdo shinshū 浄土 真宗) qui rejettent l'autorité du Honganji 本願寺 ${ }^{22}$. L'historiographie du catho-

20. Les historiens qui étudient les 《marges statutaires» (mibun-teki shüen 身分的周 縁) de la société japonaise de l'époque prémoderne s'intéressent tout particulièrement à ces religieux itinérants. Voir notamment TAKano Toshihiko 高埜利彦 (dir.), Minkan ni ikiru shūkyō-sha 民間に生きる宗教者 (Les religieux qui vivaient parmi le peuple), Tōkyō, Yoshikawa kōbunkan 吉川弘文館, 2000. En français, on trouvera un exemple dans : Anne-Marie Bouchy, Tokuhon ascète du nenbutsu : dans le cadre d'une étude sur les religieux errants de l'époque d'Edo, Paris, EPHE v vection, Centre d'études sur les religions et traditions populaires du Japon, 1983.

21. Sur le contexte historique et les caractéristiques principales des premières nouvelles religions, voir MURAKami Shigeyoshi 村上重良, Kindai Nihon no shükyō 近代日本 の宗教 (Le Japon de l'épode moderne et la religion), Tōkyō, Kōdansha 講談社, 1980, p. 11-28. En français, on consultera : Jean-Pierre BERTHON, « Millénarisme, parole et écriture dans le Japon du XIX ${ }^{e}$ siècle : le cas de la secte Maruyama-kyō », in Josef KyBURZ, François Macé, Charlotte Von Verschuer (dir.), Éloge des sources : reflets du Japon ancien et moderne, Arles, Philippe Picquier, 2004, p. 239-268.

22. Sur ces mouvements dans le cadre urbain, voir OGURI Junko 小栗純子, Myōkōnin to kakure nenbutsu 妙好人とかくれ念仏 (Les pieux pratiquants du nenbutsu et le nenbutsu caché), Tōkyō, Kōdansha 講談社, 1975. Pour une variante villageoise, il existe une étude sur le domaine de Tajiro du fief de Tsushima : CHō Tadao 長忠生, Naishinjin nenbutsu-kō 内信心念仏考 (Réflexions sur le naishinjin nenbutsu), Fukuoka, Kaichōsha 海鳥社, 1999. 
licisme japonais a eu tendance à penser cette religion en dehors de tout contexte politique et social, mais c'est bien vis-à-vis de leur environnement direct que les chrétiens cachés et les catholiques n'ont eu de cesse de se situer et de se représenter.

Notre propos se divise en trois parties. Nous montrerons d'abord que les chrétiens cachés avaient avant 1865 une activité religieuse dense et autonome, centrée sur la perpétuation de l'héritage des ancêtres et une foi inextinguible en l'existence d'un au-delà après la mort. Nous verrons ensuite que le secret entourant leur pratique religieuse a influencé fortement l'organisation sociale de ces villages ainsi que la nature des relations qu'ils pouvaient établir avec les non-chrétiens, voire avec d'autres communautés de chrétiens cachés considérées comme extérieures. Les chrétiens cachés ne s'organisaient pas seulement de manière autonome. Ils se pensaient aussi en opposition perpétuelle aux autres religions. Nous réévaluerons en dernier lieu l'impact du retour du clergé catholique sur les communautés de chrétiens cachés. À nos yeux, les prêtres ont davantage radicalisé l'identité religieuse de ces villageois que modifié intrinsèquement leurs contacts avec la société environnante. D'où l'intérêt d'étudier ces communautés sur l'ensemble du XIX ${ }^{e}$ siècle, sans opposer de manière artificielle les chrétiens cachés aux catholiques.

\section{Les caractéristiques des communautés crypto-chrétiennes}

La première partie de cette étude sera consacrée à la présentation des principales caractéristiques des communautés crypto-chrétiennes. Après avoir brièvement décrit leur organisation hiérarchique, notre attention se portera sur leurs pratiques religieuses, l'importance que ces villageois y accordaient et les bienfaits qu'ils espéraient en retirer.

\section{Organisation villageoise et organisation religieuse}

Au début de l'époque d'Edo, le bouddhisme, utilisé comme moyen de lutte contre le christianisme, a connu une forte expansion ${ }^{23}$. Alors que de nombreuses commu-

23. On trouvera un exemple sur l'expansion de la branche Sōtō 曹洞 du Zen dans Ryuken Williams Duncan, The Other Side of Zen: A Social History of Sōtō Zen Buddhism in Tokugawa Japan, Princeton, Princeton University Press, 2005, p. 13-37. 


\section{CIPANGO}

nautés étaient jusqu'alors dépourvues de temples, ou bien sous la tutelle de laïcs, le moine s'installe progressivement au village. Le bakufu, assez méfiant vis-à-vis de toute institution religieuse, essaie d'organiser et de hiérarchiser dans la mesure $\mathrm{du}$ possible tous les groupes, aussi bien shintô que bouddhiques ${ }^{24}$. L'objectif était de priver les laïcs de tout rôle religieux et de séparer le plus possible laïcs et clercs. Naturellement, l'existence des communautés de chrétiens cachés n'étant pas légale, leur organisation échappait totalement au pouvoir. Dans les enquêtes menées entre la fin du XVIII ${ }^{\mathrm{e}}$ siècle et la première moitié du XIX ${ }^{\mathrm{e}}$ siècle, les autorités tentent de connaître le plus précisément possible les structures des communautés observées. Leurs descriptions nous permettent d'entrevoir l'organisation religieuse des villages de chrétiens cachés.

La troisième enquête menée à Urakami entre 1856 et 1860 nous révèle de nombreux détails à ce sujet ${ }^{25}$. La structure hiérarchique aurait reposé sur trois éléments : un chef religieux pour tout le village ; quatre adjoints, soit un par quartier ; et une vingtaine d' « écouteurs », un par regroupement d'habitations :

C'est le sō-gashira 惣頭 [le chef de l'ensemble du groupe], qui est en charge d'enseigner aux villageois la date des fêtes religieuses ainsi que les jours fastes et néfastes ${ }^{26}$. Ceux qui sont en charge de faire connaître aux autres villageois [l'enseignement du chef] sont appelés fure-gashira 触頭 [adjoints au chef, littéralement, « celui en charge des messages »]. Les villageois sont divisés en différents groupes. Parmi les fidèles, certains sont appelés kiki-yaku 聞役 [les «écouteurs », littéralement, « celui qui est chargé d'écouter »]. Ils sont sous les ordres des adjoints au chef.

24. TAKano Toshihiko 高埜利彦 (dir.), op. cit., 2000, p. 5-10.

25. Les principaux documents de l'enquête ont été transcrits et publiés par KATAOKa Yakichi 片岡弥吉 dans TANigaWA Ken.ichi 谷川健一 (dir.), Nihon shomin seikatsu shiryō shüsei 日本庶民生活史料集成 (Compilation d'archives sur la vie quotidienne du peuple japonais), vol. 18, Tōkyō, San.ichi shobō 三一書房, 1972, p. 833-856.

26. Il s'agit probablement des jours propices à la pratique de l'agriculture ou de la pêche. Encore aujourd'hui, les dernières communautés crypto-chrétiennes continuent de respecter en apparence les recommandations de leurs chefs. KATAOKA Yakichi 片岡弥吉, Oguri Junko 小栗純子, TAMAMURo Fumio 圭室文雄, Kinsei no chika shinkō 近世の 地下信仰 (Les religions clandestines à l'époque prémoderne), Tōkyō, Hyōronsha 評論 社, 1974, p. 97-98. 


\section{祭日日繰種々の善悪等申教候ものを留頭、触事等取斗 候を触頭と唱、其場所々々にて組分いたし、信仰の内よ り聞役と唱候もの右触頭の手に付世話いたし候 ${ }^{27}$}

Sachant qu'il y avait environ 3500 chrétiens cachés à Urakami, on peut penser que le chef religieux du village était une personnalité importante. Pour Ebisawa Arimichi 海老沢有道, il était fréquent que ces chefs cumulent aussi les offices laïques (chef de village, adjoint au chef, etc.) durant le « siècle chrétien ${ }^{28}$. La situation semble avoir évolué à la fin de l'époque d'Edo, car Kichizō, le chef religieux du village lors de la troisième enquête, n'avait apparemment aucune charge publique.

La suite du document précédemment cité apporte une précision supplémentaire : la charge de responsable religieux était, semble-t-il, héréditaire :

Le père de Kichizō, Rigorō, était le chef [des chrétiens cachés]. C'est lui qui enseignait les jours de fête et le calendrier aux autres. Au $8^{\mathrm{e}}$ mois de l'année du singe [août 1848], il est mort de maladie. Pendant trois ans, alors que personne ne l'avait remplacé, les fidèles de la religion hétérodoxe ont enjoint Kichizō de prendre la succession de son père. Kichizō est ainsi le chef depuis l'année du sanglier [1851].

親利五郎惣頭いたし居候節同人より異宗の祭日并日繰 其外等申教受、去る申年八月同人病死後三ヶ年程も惣頭 中絶いたし居候処、異宗のもの共任申勧同亥年より此も の惣頭に相立 ${ }^{29}$

Dans leur correspondance, les missionnaires français décrivent aussi à de nombreuses reprises la hiérarchie religieuse des villages de chrétiens cachés. Ces textes mentionnent en général deux charges : les chefs de prière et les bap-

27. TANigawa Ken.ichi 谷川健一 (dir.), op. cit., 1972, p. 834.

28. EBISAWA Arimichi 海老沢有道, Kirishitan no dan.atsu to teikō キリシタンの弾圧 と抵抗 (Répression et résistance des catholiques japonais), Tōkyō, Yūzankaku shuppan 雄山閣出版, 1981, p. 186.

29. TANigawa Ken.ichi 谷川健一 (dir.), op. cit., 1972, p. 834. 


\section{CIPANGO}

272 Cahiers d'études japonaises n² 21

tiseurs. Les termes employés sont différents de ceux que l'on retrouve dans les rapports des hommes du préfet de Nagasaki. Toutefois, ils renvoient probablement aux mêmes personnes. Dans un document de décembre 1866, adressé par Bernard-Thadée Petitjean (1829-1884) ${ }^{30}$ à la Congrégation pour la propagation de la foi (Congregatio de Propaganda Fide), on lit :

Au moment où les premiers chrétiens se sont fait connaître à nous, il y avait dans chaque village un baptiseur et un chef de prières. Le premier administrait le baptême aux petits enfants, tandis que l'autre récitait l'Oraison dominicale, la Salvation Angélique \& le Symbole des Apôtres. Mais ces prières étaient plus ou moins défigurées et plusieurs n'en comprenaient pas même le sens. Quant au baptiseur, il se choisissait un disciple qu'il instruisait pendant cinq ans et à qui il laissait ensuite la charge et le soin de baptiser après lui ${ }^{31}$.

Le missionnaire ne dit pas si ces charges étaient héréditaires, mais il précise que « chaque baptiseur formait un disciple, à qui il transmettait, en héritage, le ministère [=la charge de baptiseur] ainsi que la manière de baptiser $\gg^{32}$. Si ces deux passages n'indiquent pas précisément que les baptiseurs léguaient leur charge à un membre de leur famille, l'idée de lignée transparaît en revanche assez clairement, d'autant plus qu'ils choisissaient eux-mêmes leur successeur.

On comprend donc que le rôle de ces chefs religieux était de conférer le baptême, d'enseigner le calendrier aux fidèles, de prier, mais aussi, comme on va le voir, d'accueillir les fidèles lors de réunions religieuses. Notons que l'on trouve dans d'autres groupes clandestins, notamment les amidistes clandestins, une organisation similaire, avec des chefs en charge de plusieurs centaines de fidèles, comme dans le domaine de Tajiro 田代 du fief de Tsushima 対馬 ${ }^{33}$. Ces chefs, appelés $z e n c h i s h i k i$ 善知識 (littéralement 《 [celui qui possède] la bonne connaissance »), faisaient passer un rite initiatique censé garantir au fidèle le salut d'Amida.

30. Bernard-Thadée Petitjean (1829-1884), prêtre des Missions étrangères de Paris, devient vicaire apostolique du Japon en 1866.

31. AMEP, vol. 569, fol. 1923-1934, 18 décembre 1867.

32. Le passage est en latin : Quisque baptizator discipulum educabat, cui simul et ministerium et modum baptizandi in haerditatem transmittebat.

33. CHō Tadao 長忠生, op. cit., 1999, p. 54-55. 
Ces quelques éléments suffisent à démontrer que les chrétiens cachés avaient érigé une hiérarchie au sein de leurs communautés. Leur existence n'est pas secondaire. Ces organisations étaient sans nul doute un facteur d'identification important dans une société où le paysan se pensait principalement comme le membre d'une communauté villageoise au sein de laquelle les liens sont extrêmement puissants ${ }^{34}$.

\section{Un calendrier rythmé par les pratiques religieuses}

Les enquêtes menées par les autorités sont aussi l'occasion de descriptions minutieuses des pratiques et rites des chrétiens cachés. Ces documents nous permettent de cerner l'importance des considérations religieuses dans l'organisation du quotidien. Chaque village possédait un calendrier propre, avec des rites et fêtes variant légèrement d'une localité à l'autre. Cependant, l'ensemble des chrétiens cachés respectaient visiblement une période de jeûne pour le carême, calculée à partir de la Nativité, et ils suivaient toute l'année des interdits alimentaires à des jours précis. L'enquête sur Urakami rapporte ainsi que :

Le $66^{\mathrm{e}}$ jour après le Kinta ${ }^{35}$ s'appelle le kuhatta. À partir de ce moment et pour une période de 46 jours, les villageois d'Urakami sont dans une période de tristesse ${ }^{36}$. Ils s'abstiennent de manger de la viande. Le jour suivant la fin de cette période est appelée « jour de la joie ». Il s'agit d'une fête en l'honneur de Sainte Marie ${ }^{37}$. Les villageois font des offrandes. Les adjoints se rendent chez le chef. Après avoir lu des sûtras, ils partagent un repas. Leur calendrier fonctionne ainsi : le $46^{\mathrm{e}}$ jour - le premier - est appelé domengosu, le second shikuta, le troisième terusha, le quatrième kuwatta, le

34. Sur l'aspect communautaire de la vie rurale durant l'époque d'Edo, voir notamment WatAnabE Takashi 渡辺尚志, Hyakushō no chikara - Edo jidai kara mieru Nihon 百 姓の力ー江戸時代から見える日本 (Le pouvoir des paysans : le Japon au prisme de l'époque d'Edo), Tōkyō, Kashiwa shobō 柏書房, 2008.

35. L'officier fait référence à la nativité du Christ.

36. Dans le texte, « kanashimi no uchi » 悲の内, c'est-à-dire la période du carême.

37. Le carême s'achève bien entendu avec la résurrection du Christ. Cette « erreur » est sans doute le témoignage de l'attachement des chrétiens cachés à la figure de Marie. 


\section{CIPANGO}

cinquième kinta, le sixième sahata, le septième setsuta ${ }^{38}$. Cette période de sept jours se répète ensuite. Lors du septième jour, ils ne mangent pas de viande. Dans cette religion, ils ont des jours de félicité, des jours où il faut ensemencer et d'autres où il ne faut pas le faire, et toutes sortes de jours fastes et néfastes. Tous les septièmes jours, les adjoints se réunissent chez le chef religieux pour apprendre ces dates.

前書キンタに当り候日より六十六日目をクハッ夕と 唱、夫より月数四十六日の間悲の内と申鳥獣の類食用不 致相慎、右日数相立候翌日を悦の日と唱、右は則ハン夕 マルヤの祭日に付備物いたし触頭共此もの宅江打寄読経 の上酒食相催日繰の仕法は右四十六日目を初日ドメンゴ スと定、二日目シク夕、三日目テルシャ、四日目クワッ 夕、五日目キン夕、六日目サ八夕、七日目セツ夕と追々 に七日宛繰、其日には鳥獣等不食日、悦ひ事田畑蒔付等 の用不用種々の善悪有之候に付、右次第七日目毎に触頭 共此もの方江承に相越候 ${ }^{39}$

Ce passage rend manifeste que les pratiques religieuses étaient omniprésentes dans la vie des chrétiens cachés. Ces dernières comprenaient des jours de jeûne, la période du carême, les différentes fêtes, les jours fastes et néfastes pour l'agriculture, mais aussi les baptêmes et les cérémonies parallèles organisées lors des enterrements ${ }^{40}$. Ajoutons qu’à Urakami, les chrétiens cachés se réunissaient deux à trois fois par mois chez le chef religieux ou l'un de ses adjoints pour prier et manger ensemble :

Deux ou trois fois par mois, les membres de la confrérie du thé [chakō 茶講] se réunissent chez le chef ou bien chez l'un de ses

38. Il s'agit des jours de la semaine en portugais : domingo, segunda feira, terça feira, quarta feira, quinta feira, sexta feira, sábado.

39. TANigawa Ken.ichi 谷川健一 (dir.), op. cit., 1972, p. 834-835.

40. Les pratiques des chrétiens cachés lors des enterrements durant l'époque d'Edo sont assez mal connues. Au sujet des rites funéraires dans les communautés encore actives aujourd'hui, on peut se référer à MIYAZAKI Kentarō 宮崎賢太郎, op. cit., 1996, p. 159-170. 
adjoints. Mais, comme ils sont nombreux, les groupes se rendent à ces réunions séparément, et dans un ordre bien établi. À tour de rôle, chaque groupe se réunit, et après avoir récité la prière Garasusa ${ }^{41}$, dont nous avons parlé auparavant, ils partagent un repas.

\section{月々両三度宛茶講と唱連中のもの共此もの又は触頭の 宅江会合いたし候得共、大勢故共組々にて順を立て置、 代わる々寄合前同様ガラスサ等を唱候後酒給合 ${ }^{42}$}

De telles pratiques semblent avoir été suivies par l'ensemble des chrétiens cachés avant le retour du clergé catholique. Dans un village que nous avons étudié plus précisément ${ }^{43}$, celui d'Imamura, dans le fief de Kurume, les chrétiens suivaient un calendrier similaire avec une « période de tristesse » (le carême) également calculée par rapport à la Nativité. Le reste de l'année, ils s'abstenaient de consommer de la viande certains jours de la semaine, à l'instar des habitants d'Urakami. Si les sources ne mentionnent pas de « confrérie du thé » (chakō), on sait que les chrétiens cachés de ce village se réunissaient le vingtième jour de chaque mois, pour prier sur la tombe d'un catholique vénéré comme l'ancêtre de toute la communauté, et chez un villageois influent lorsque le village était frappé

41. Il s'agit de l'Ave Maria dont la prière commençait en japonais par les mots « Garasusa michi michi... »(Pleine de grâce). Voir Tanigawa Ken.ichi 谷川健一 (dir.), op. cit., 1972 , p. 833.

42. Ibid., p. 834 .

43. Nous avons consacré un article à ce village : Martin Nogueira Ramos, « Le Choix de la conversion dans les villages de descendants de chrétiens : le cas d'Imamura dans la province de Chikugo (1867-1879) », in Jean-Michel Butel, Makiko Andro-UedA (dir.), Japon pluriel 9: actes du neuvième colloque de la Société française d'études japonaises, Arles, Philippe Picquier, 2014a, p. 375-384. 
par la maladie ou un malheur quelconque ${ }^{44}$.

Si le calendrier et l'organisation des communautés de chrétiens cachés sont donc relativement bien connus à travers les différentes enquêtes effectuées à la fin de l'époque d'Edo, leur origine est souvent plus mystérieuse. Elles sont probablement les héritières des confréries laïques du XVI ${ }^{\mathrm{e}}$ et $\mathrm{XVII}^{\mathrm{e}}$ siècle. Rappelons que face à la faiblesse numérique du clergé et à l'extension géographique de la chrétienté, les convertis du « siècle chrétien » s'étaient très tôt organisés de manière autonome pour mener à bien les différents rites (enterrements, rassemblements pour le dimanche, etc.), transmettre les rudiments de doctrine aux fidèles ou préparer la venue du prêtre dans la communauté ${ }^{45}$. Cette forte implication des laïcs dans la vie religieuse n'était cependant pas le propre des premiers catholiques ni des chrétiens cachés. Dans une étude sur les fidèles de l'École véritable de la Terre pure du district de Kanbara 蒲原 ${ }^{46}$, l'historien Nagura Tetsuzō 奈倉哲三 fait remarquer qu'à la fin de l'époque d'Edo (période du bakumatsu), une partie d'entre eux se détournait des cérémonies proposées par le clergé bouddhique, pour privilégier

44. Le village d'Imamura est assez bien connu grâce à une enquête menée par les autorités du fief en 1868. Le résultat de ces investigations est compilé dans un document appelé Jash ü-mon ikken kuchigaki-chō 邪宗門一件口書帳 (Recueil de dépositions relatives à l'affaire des hérétiques), transcrit et publié par Kunitake Tetsuo 国武喆生 (dir.) et d'autres catholiques de la région, dans « Jashū-mon ikken kuchigaki-chō - Mihara-gun Imamura 》 邪宗門一件口書帳一御原郡今村 (Transcription du Jashu-mon ikken kuchigaki-chō : Imamura dans le district de Mihara), Kurume kyōdo-shi kenkyu-shi 久留 米郷土史研究誌, n ${ }^{\circ} 6$, Kurume, Kurume kyōdo-shi kenkyū-kai 久留米郷土史研究会, 1976, p. 1-23.

45. Sur l'organisation autonome des laïcs et le rôle des confréries, voir Kawamura Shinzō 川村信三, Kirishitan shinto soshiki no tanjō to hen.yōキリシタン 信徒組織の誕生と変容 (La naissance des confréries catholiques au Japon et leur évolution), Tōkyō, Kyōbunkan 教文館, 2003. Notons que l'autonomie des chrétientés locales n'est pas le propre de la mission du Japon. Pour pallier sa faiblesse numérique, les missionnaires confiaient souvent l'essentiel de l'organisation des chrétientés locales aux laïcs. Sur les missions de Chine et de Corée, on trouvera de stimulantes réflexions dans la thèse de doctorat de Pierre-Emmanuel Roux, La Trinité antichrétienne : essai sur la proscription du christianisme en Chine, en Corée et au Japon, thèse de doctorat de l'École des hautes études en sciences sociales, sous la direction de Pierre-Étienne Will, 2013.

46. Kanbara se trouve dans le département actuel de Niigata. 
celles organisées par les laïcs ${ }^{47}$.

\section{La religion, un patrimoine à conserver}

La période d'Edo voit le culte rendu aux ancêtres se généraliser à toute la population et devenir la prérogative du chef de famille. Les funérailles et le service en l'honneur des âmes des ancêtres (kuyō 供養) sont menés sous sa direction. Les familles ont une tombe (bohi 墓碑), un autel bouddhique (butsudan 仏壇), et un registre servant à noter les noms des défunts (kako-chō 過去帳). La logique familiale devient de plus en plus importante, même chez les petits propriétaires terriens. Chaque chef de famille reçoit de son prédécesseur un « nom de maisonnée » (kamei 家名), la «propriété familiale 》(kasan 家産) et une 《activité propre à la maisonnée » (kagyō家業), mais aussi le droit de célébrer le « culte des ancêtres » (senzo saishi 先祖祭祀) ${ }^{48}$.

Dans les documents relatifs aux chrétiens cachés et catholiques du XIX ${ }^{e}$ siècle, la place prépondérante accordée aux parents et ancêtres est manifeste. L'appartenance religieuse se trouve justifiée presque entièrement par la tradition familiale et ancestrale. Un épisode que nous rapportent les missionnaires à la fin de l'année 1867 en offre une bonne illustration. Le préfet de Nagasaki interroge l'une des principales figures d'Urakami, Takaki Sen.emon 高木仙右衛門 (18241899), qui a décidé de se convertir au catholicisme. Ce dernier invoque le legs religieux de ses ancêtres pour justifier le fait qu'il ne puisse renoncer à sa religion :

[Le préfet de Nagasaki dit] : « En suivant la voie de Chaca [Shaka 釈迦, Bouddha], qui ordonne aussi d'obéir aux parents,

47. NAGURA Tetsuzō 奈倉哲三, Bakumatsu minshū bunka ibun - Shinshū monto no shiki 幕末民衆文化異聞一真宗門徒の四季 (Histoire méconnue de la culture populaire durant le bakumatsu : les quatre saisons des fidèles de l'École véritable de la Terre pure), Tōkyō, Yoshikawa kōbunkan 吉川弘文館, 1999, p. 163-166.

48. ŌTō Osamu 大藤修, «Shōkeiei, ie, kyōdōtai »小経営 家 共同体 (Microgestion, maison et communauté), in REKISHI-GAKU KENKYŪ-KAI 歴史学研究会, NiHON-SHI KENKYŪ-KAI 日本史研究会編 (dir.), Nihon-shi kōza - Kinsei shakai-ron 日本史講座一近世社会論 (Cours d'histoire japonaise : sur la société de l'époque prémoderne), vol. 6, Tōkyō, Tōkyō daigaku shuppankai 東京大学出版会, 2005, p. 9-12. 
de respecter les officiers, et de faire du bien aux prochains, comme la loi chrétienne, tu feras le salut de ton âme. Fais dans la loi de Chaca ce que tu fais dans la loi chrétienne, et ce sera la même chose, seulement ne sois plus chrétien, car cette religion vient de l'étranger et elle est proscrite. » « La loi de Chaca, reprit Chenniémon [Sen. emon], a d'abord commencé aussi par venir de l'étranger, et c'est parce que nos ancêtres ont trouvé la religion chrétienne meilleure, qu'ils l'ont suivie, et nous l'ont léguée, impossible de l'abandonner, et si je meurs pour elle, j'ai la confiance que j'irai au Ciel. ${ }^{49}$

L'idée que la religion a été transmise de génération en génération est souvent mentionnée dans les enquêtes menées par les autorités. Dans un document récapitulant la troisième affaire du village d'Urakami, le préfet de Nagasaki explique que les chrétiens cachés se sont transmis cette religion sans vraiment réfléchir à son contenu :

Peu nombreux sont ceux qui parmi les paysans ignares des terres reculées savent écrire. La grande majorité est illettrée. Sans se poser de question, ils transmettent [de génération en génération] la religion hétérodoxe [ish $\bar{u}$ 異宗]. Ils ne savent même pas de quelle religion il s'agit.

元来邊鄙愚昧の百姓共文字等書覚候もの少く多分は無 筆の儀無思慮異宗とのみ申伝何宗旨と申弁別も無之 ${ }^{50}$

D'autres documents attestent du poids de la tradition familiale. Les chrétiens cachés pratiquent leur religion car leurs parents leur ont dit de le faire. Mais aux yeux des officiers, ils ne comprennent pas le sens de leurs actes. Lors de la première enquête d'Urakami (1790-1796) ${ }^{51}$, un chrétien parle de la prière en ces termes :

49. AMEP, vol. 569, fol. 4099-4105, 20 décembre 1867.

50. TANigawa Ken.ichi 谷川健一 (dir.), op. cit., 1972, p. 852.

51. Des sources relatives à cette enquête sont publiées dans ibid., p. 763-832. 
À propos de la prière Amen-Jésus ${ }^{52}$, mes parents m'ont dit de prier de cette façon. Même si je n'en savais pas la raison, j'ai prié Amen-Jésus. Jusqu'à présent j'ai continué de réciter cette prière sans savoir si cela était une bonne ou une mauvaise chose.

アメンジュスと唱候事は親より右の通りに唱候様申候 間、訳合は不存候へども唱申候。宜事共悪敷事共不相弁 是迄唱来申候 ${ }^{53}$

À Imamura, un villageois, qui rapidement décide de se convertir au catholicisme, explique que personne dans sa communauté ne comprenait quelle était l'origine, donc la raison, de leur pratique religieuse et rituelle :

Ce dont je vous ai parlé au début, le fait qu'il ne faille pas manger de viande, etc., jusqu'à présent, personne dans le village n'en connaissait la raison. Or moi, en étudiant le sens véritable du christianisme [auprès des missionnaires], j'en ai compris les enseignements principaux.

初発申上候四足二足不食訳等、是迄村方において委 敷承知罷在候者無御座候処、此節私儀宗法の深意稽古仕 候、大略相分り候義御座候 ${ }^{54}$

Aujourd'hui encore, on retrouve cette absence de questionnement sur la tradition religieuse parmi les chrétiens cachés restants, notamment à Ikitsuki 生月 ${ }^{55}$. Ils récitent des prières en latin sans en connaître le sens. Rares sont également ceux qui connaissent l'origine des fêtes du calendrier ${ }^{56}$. Certes, il n'est pas certain que l'on puisse transposer complètement la situation des chrétiens cachés actuels, descendants de ceux qui n'ont pas reconnu les missionnaires comme maîtres de leur

52. C'est par ces deux mots que les chrétiens cachés finissaient leurs prières. Christal WHELAN, op. cit., 1996, p. 113.

53. TANigawa Ken.ichi 谷川健一 (dir.), op. cit., 1972, p. 790.

54. Kunitake Tetsuo 国武喆生 (dir.), op. cit., 1976, p. 5.

55. Île située au nord-ouest du département de Nagasaki.

56. MiYazaKi Kentarō 宮崎賢太郎, op. cit., 1996, p. 76 ; 106-107. 
religion, sur celle des communautés du XIX ${ }^{\mathrm{e}}$ siècle, qui avaient à en examiner la possibilité. Comme le montre le passage cité ci-dessus, des descendants de chrétiens voulaient étudier la religion catholique auprès des prêtres pour comprendre le sens de leur tradition.

L'existence même et la transmission de génération en génération du Tenchi hajimari no koto témoignent de ce questionnement sur le sens de la foi de la communauté. Selon l'anthropologue Kamiya Takehiro 紙谷威広, la création de ce recueil de mythes était devenue nécessaire pour aider les membres à comprendre l'existence de leur foi, et la raison pour laquelle elle différait de celle des autres religions qu' ils côtoyaient dans leur environnement immédiat ${ }^{57}$.

\section{Les bienfaits de la foi : l'abondance en ce monde, le salut dans l'au-delà}

Village et ancêtres ne font qu'une seule et même identité. Plus exactement : l'identité de la communauté est déterminée par le patrimoine ancestral, et se définit par rapport à des pratiques et un culte rendu à une divinité particulière. Il est pourtant difficile d'imaginer que ces villageois aient tous suivi ces pratiques dans le seul objectif de se plier à la norme communautaire et de respecter la tradition familiale. Quels bénéfices les chrétiens cachés cherchaient-ils à obtenir de leur religion ? Lorsqu'ils sont interrogés par les officiers, ils justifient leur pratique aussi bien par la recherche de bienfaits en ce monde ${ }^{58}$ que par la croyance en l'existence d'un paradis après la mort. Souvent, ils juxtaposent dans la même phrase ces deux éléments. À Urakami, voici ce qu'on peut lire dans le rapport sur le chef religieux du village, Kichizō :

Ceux qui croient en cette religion ont ici-bas de bonnes récoltes dans leurs champs. En outre, un ensemble de choses se déroule de la meilleure des façons pour eux, et leurs vœux sont exaucés. Ils jouissent de la félicité et de bienfaits, et augmentent leur espérance

57. Kamiya Takehiro 紙谷威広, op. cit., p. 26-28.

58. Il s'agit d'une constante de la religiosité populaire de l'archipel. Les spécialistes japonais emploient le terme de genze riyaku 現世利益. À ce sujet, on lira à profit : Ian Reader, Tanabe George J., Practically Religious: Worldly Benefits and the Common Religion of Japan, Honolulu, University of Hawai'i Press, 1998. 
de vie. Dans le monde à venir, ils vont tous au paradis, parents, épouses et enfants.

信心いたし候ものは現世にて田畑作物出来方宜敷、其 外諸事仕合能、諸願成就、福徳延命、来世は親妻子兄弟 一同ハライソ江 ${ }^{59}$

L'officier ayant mené les entretiens insiste sur les bienfaits que les chrétiens cachés pensent obtenir en allant au paradis :

Il se transmet qu'après leur résurrection [au paradis], ils jouissent d'un bonheur illimité. Cette religion leur apportant ce bienfait extraordinaire, ils ne prient que Hanta Maruya [Sainte Marie], et récitent matin et soir leurs prières.

再生いたし無限歓楽を得候旨承伝右様恵深き事故一途 にハンタマルヤを念し朝タウラッショ ${ }^{60}$

À Imamura, les raisons invoquées sont similaires:

Il faut sans fainéanter respecter ce calendrier, et aussi réciter sans cesse les prières de Jésus et Marie (il s'agit de bouddhas et de prières comme le nenbutsu ${ }^{61}$ ). Car celui qui suit cela et croit dans cette religion évite en ce monde les choses funestes et les malheurs, et après la mort se rend au paradis (gokuraku).

年中不急相守候様、且又不断ゼゾウス マリヤ（仏 の如 念仏) さまと唱候様、右様致信心候えば今生にては 悪事災難を遁れ、死してはパライソ（極楽）え参り ${ }^{62}$

À Amakusa :

59. Tanigawa Ken.ichi 谷川健一 (dir.), op. cit., 1972, p. 833.

60. Ibid., p. 833. Le terme utilisé pour « prière » est celui des chrétiens cachés urassho en biragana, qui vient du latin oratio.

61. Les passages entre parenthèses sont des commentaires insérés par les officiers en charge de l'enquête. Ils avaient pour but de rendre intelligible le propos des chrétiens.

62. Kunitake Tetsuo 国武吉生 (dir.), op. cit., 1976, p. 2. 
Ils avaient appris [de leurs parents] que ceux qui croyaient dans la divinité principale de leur religion, Dieu, le Maître du Ciel et de la Terre, et en sa mère Sainte Marie, seraient heureux, qu'ils échapperaient au désastre et à la maladie, et que leurs récoltes et la pêche seraient bonnes. En outre, tous les croyants, parents, épouses, enfants et frères, renaîtraient après leur mort dans le royaume des cieux [tenjōkai 天上界] et y jouiraient de l'aisance.

本尊は天地の主デウス、右母はサンタマルヤと申仏の 由常々信仰いたし候得ば福徳を得無病災作物漁方等仕合 能、来世親妻子兄弟一同天上界に生し安楽の身と成候段 承伝 ${ }^{63}$

En général, les enquêtes n'offrent guère plus de détails sur le paradis des chrétiens. Elles en rapportent seulement la taille prétendue : « une surface de 100000 lieues s'étendant dans les quatre directions » (ハライソと申所は十万里四方 ${ }^{64}$ ). Pour des officiers, il s'agit du «paradis du ciel » (tenjō no gokuraku 天上の極楽). Le gokuraku est en général le terme par lequel on désigne la Terre pure du bouddha Amida. La dimension familiale de ce paradis est aussi très forte. À Amakusa et Urakami, c'est la famille réunie qui se rendra après la mort en ce lieu. À Imamura, les chrétiens se transmettent de génération en génération l'idée que s'ils respectent la tradition religieuse du village, ils iront au paradis et retrouveront ainsi leurs ancêtres.

Il faut noter cette distinction permanente entre le monde présent et l'au-delà. Si les chrétiens cachés espèrent obtenir des bienfaits en ce monde, comme d'ailleurs les croyants des autres religions installées au Japon, la notion de salut de l'âme, de vie après la mort, est restée vivace parmi ces communautés. Des historiens chrétiens comme Kataoka Yakichi 片岡弥吉ou Ebisawa Arimichi 海老沢有道 considèrent que cette recherche des bienfaits matériels par le biais de la religion est le résultat d'une déformation progressive du message porté à l'origine par les missionnaires. Il est vrai que beaucoup de mouvements populaires du XIX ${ }^{\mathrm{e}}$ siècle japonais, que ce soit les nouvelles religions, les pèlerinages massifs à Ise comme en

63. TAnigawa Ken.ichi 谷川健一 (dir.), op. cit., 1972, p. 852.

64. Ibid., p. 834. 
1830, ou encore les danses frénétiques observées lors de rassemblements appelés ee janaika ええじゃないか(1867-1868), manifestent la recherche d'une assistance divine en ce monde. Les révoltes paysannes réclamant un renouveau du monde (yonaoshi) révèlent de façon similaire le souhait d'un monde égalitaire où il n'y aurait plus de laissés-pour-compte ${ }^{65}$. Ce type d'explication relève pourtant selon nous d'une vision trop stéréotypée de la piété. On a pu montrer par exemple que pour les catholiques français de l'époque prémoderne la religion était aussi bien un moyen d'obtenir le salut dans l'au-delà que de se prémunir contre la mauvaise fortune en ce monde ${ }^{66}$. Pour la plupart des mouvements religieux japonais d'Edo, c'est dans le monde présent que le changement est d'abord attendu. Les chrétiens cachés, eux, séparent clairement le présent du paradis qui surviendra après la mort.

\section{Une communauté fermée aux autres}

Quatre éléments permettent aux chrétiens cachés de se distinguer de leur environnement direct : une organisation religieuse autonome, un calendrier liturgique qui rythme l'année, l'assimilation de cette religion à un héritage précieux légué par les ancêtres et une croyance dans le paradis, lieu où tous les chrétiens iront après la mort. Nous allons maintenant voir comment ces communautés de chrétiens cachés s'organisent et se pensent en comparaison à l'extérieur. Le premier élément fondamental de leur organisation tient dans le secret qui entoure leur pratique.

\section{L'importance du secret}

Face à l'application de plus en plus radicale des mesures de proscription du chris-

65. On trouve une présentation synthétique des aspirations religieuses du peuple au XIX $^{\text {e }}$ siècle dans Harry D. Harootunian, "Late Tokugawa Culture and Play", in Marius B. Jansen (dir.), The Emergence of Meiji Japan, New York, Cambridge University Press, 1995, p. 100-116.

66. Sur les croyances des catholiques français du XIX ${ }^{\mathrm{e}}$ siècle, voir : Philippe BoutRY, «Les Mutations des croyances » in Philippe Joutard (dir.), Histoire de la France religieuse, tome 3 : Du roi Très Chrétien à la laïcité républicaine $\mathrm{xviii}^{e}-\mathrm{xix}^{e}$ siècle, Paris, Seuil, 2001, p. 465-510. 
tianisme au $\mathrm{XVII}^{\mathrm{e}}$ siècle, les catholiques japonais ont eu trois choix : apostasier, continuer de pratiquer ouvertement leur religion, et donc affronter la répression, ou alors renier formellement et pratiquer en secret. C'est la troisième solution qui a été privilégiée dans la majorité des villages du nord de Kyūshū. Cette dimension secrète était toujours d'actualité au XIX ${ }^{\mathrm{e}}$ siècle. La formule du sacrement du baptême, considérée comme fondamentale par la plupart des chrétiens cachés, n'était connue que par quelques personnes. Elle se transmettait secrètement comme à Imamura :

Dans notre village, depuis les temps anciens, il n'y a qu'une seule personne en charge du baptême. On l'appelle sazuke [littéralement « celui qui confere »]. [...] Il s'agit d'un rite extrêmement secret. L'homme en charge de cette tâche s'appelait Matahachi, mais il est mort le $10^{\mathrm{e}}$ jour du $9^{\mathrm{e}}$ mois de l'année du lièvre [1867]. On dit que Matahachi avant de mourir a enseigné à Chūkichi comment accomplir ce rite. Cette prière et ce rite, jusqu'à présent, à part Matahachi puis Chūkichi, personne ne les connaissait dans le village.

於村方古来より授けと申役目只志人に御座候て $[. .$.$] 極$ 秘密の伝法候て、此役又八と申者相勤居候処、去卯九月 十日相果申候。右死に際に忠吉と申者え口伝仕候由、此 唱事、是迄右授けの外壱人も存候者無御座候 67

C'est également ce que confirme un chrétien d'Urakami quelques jours après l'établissement des premiers contacts avec les missionnaires français en 1865 :

Le baptême y a toujours été administré. Paolo le père de famille qui nous a donné avec bonheur ce consolant détail n’a pu nous répéter les paroles du sacrement, parce qu'il n'y en a qu'un petit nombre qui soit au courant de la formule, nous a-t-il dit ${ }^{68}$.

$\mathrm{Au} \mathrm{XVI}^{\mathrm{e}}$ et $\mathrm{XVII}^{\mathrm{e}}$ siècle, les jésuites estimaient que tout catholique devait connaître la formule du baptême. Dans le Dochiriina kirishitan どちりいなきり

67. Kunitake Tetsuo 国武喆生 (dir.), op. cit., 1976, p. 4.

68. AMEP, vol. 569, fol. 1268-1275, 22 mars 1865. 
Lたん (La doctrine chrétienne) ${ }^{69}$, le catéchisme le plus diffusé par la Compagnie de Jésus au Japon, il est indiqué clairement que quiconque, homme ou femme, doit baptiser en cas d'absence du prêtre ${ }^{70}$. Avec le temps, le baptême est devenu l'apanage de quelques personnes dont la position était éminente au sein des communautés crypto-chrétiennes. On verra par la suite que le baptême était considéré comme essentiel à l'accomplissement du salut.

On retrouve dans d'autres mouvements populaires du Japon de l'époque d'Edo des chefs religieux organisant des rites initiatiques secrets. C'est le cas des zenchishiki qui sont à la tête de communautés amidistes clandestines. Celui qui aspire à rejoindre le groupe suit plusieurs rites secrets, et n'est pas informé de la date ni du lieu de la dernière cérémonie au cours de laquelle il est assuré de recevoir le salut. Celle-ci se déroule en général de nuit, dans un lieu à l'abri des regards. L'aspirant n'apprend l'identité même du zenchishiki qu'au moment de la cérémonie ${ }^{71}$.

Nous avons vu que les chrétiens d'Urakami se réunissaient secrètement deux à trois fois par mois pour prier et faire un repas communautaire. L'officier en charge de l'enquête explique que les chrétiens « détestent» (itohi 厭ひ) que des gens n'appartenant pas au groupe les observent :

Lors de leurs réunions, ils détestent que des personnes viennent [les observer]. Parmi les «écouteurs », une ou deux personnes montent la garde à tour de rôle à la porte de la maison où se tient la réunion. Si une personne étrangère au groupe apparaît, ils le font savoir sans tarder. Ils rangent les bouddhas sortis pour l'occasion, et arrangent le lieu comme s'ils faisaient un repas ordinaire.

右会合いたし候節は餘人立越候儀を厭ひ、前書聞役の 内より一両人門ど先江代るがわる番致連外のもの参り候

69. L'ouvrage a été rédigéà la fin du XVI ${ }^{\mathrm{e}}$ siècle. Il était visiblement destiné à aider les chefs de communautés catholiques. On trouve une transcription du texte dans : Hubert CiesLiK, Dor Tadao 土井忠生, EBISAWA Arimichi 海老沢有道, ŌTSUKA Mitsunobu 大塚光 信, op. cit., 1970, p. 13-81.

70. Ibid., p. 66.

71. On trouve une description de ce rite initiatique dans la deuxième moitié du XVIII ${ }^{\mathrm{e}}$ siècle dans OGURI Junko, op. cit., 1975, p. 94-96. 
得は早速為相知取出し置候仏相仕舞一と通り酒給合候体 に仕成候儀 ${ }^{72}$

On peut expliquer cette attitude par la crainte de la dénonciation. Cependant, grâce à d'autres documents, on comprend que le maintien du secret est aussi, et surtout, un élément de leur pratique ayant pris un caractère religieux. À Urakami, ceux qui parviennent à garder le secret, même sous la torture, sont l'objet d'un culte particulier. Alors que le catholicisme exalte ceux qui souffrent le martyre au nom du Christ, les chrétiens cachés vénèrent ceux qui parviennent à dissimuler leur foi :

Si par hasard, ils sont découverts et qu'une enquête est menée à leur sujet, ils ne doivent pas vaciller, et même s'il leur faut affronter la torture, ils considèrent cela comme une épreuve voulue par leur religion. S'ils ne dévoilent pas leur religion, et que pour cette raison ils sont sévèrement punis, les villageois d'Urakami disent qu'ils ont atteint l'éveil en ce monde. Ils vénèrent tout particulièrement ceux qui, lors des interrogatoires, sont parvenus à cacher leur religion jusqu'au bout. Il se dit que les habitants du village notent leur nom et que pour l'éternité ils leur dédient des offrandes lors des offices réalisés en faveur des morts. Les parents disent sans relâche [à leurs enfants] qu'il est fondamental qu'ils ne dévoilent pas leur religion à autrui.

万一及露顕吟味受候場合に至候はは不動心を凝し何程 責問等に逢ひ候ても宗旨の修行と観念いたし及白状間敷 共上にも察度受㛜科に被行候得は即身成仏を遂候趣にて 先年より逢詮議不及白状事済相成候もの共は格別に尊敬 いたし、死後は名前を書留置永世忌日には供物等相備候 事の由、都て宗体の儀を洩さざる心掛肝要の旨不断親共 より及承罷在 ${ }^{73}$

72. Tanigawa Ken.ichi 谷川健一 (dir.), op. cit., 1972, p. 834.

73. Ibid., p. 834. 
Dissimuler sa foi jusqu'au bout est donc un acte méritoire. Pour d'autres communautés, le maintien du secret était aussi un moyen d'obtenir le salut. À propos d'Imamura, un administrateur (ōjōya 大庄屋) dit que dans ce village dévoiler sa foi est un obstacle au salut (shöge 障碍) :

Originellement, il s'est transmis [à Imamura] que dévoiler sa religion à autrui est un obstacle au salut. Jusqu'à présent, même les villageois sots et puérils ne dévoilaient pas leur religion aux gens des autres cultes.

全体、切支丹宗門の儀、其宗旨の儀を口外仕候得ば障 碍に相成候趣申伝候由にて、是迄暗愚幼稚の者も他宗の 者えは口外不仕候 ${ }^{74}$

\section{Une communauté repliée sur elle-même}

L'importance attribuée au secret chez les crypto-chrétiens semble avoir eu un grand impact sur leurs contacts avec les autres communautés. Dans plusieurs documents, aussi bien français que japonais, on apprend que les chrétiens cachés évitent, dans la mesure du possible, tout mariage avec des personnes étrangères au groupe. Ceci peut avoir, dans de petites communautés, des conséquences allant à l'encontre des règles de l'Église car celle-ci interdit par principe les mariages de personnes parentes entre elles en ligne directe ou en ligne collatérale jusqu'au quatrième degré inclus. Dans un document de mai 1866, un missionnaire s'interroge sur la posture à adopter face aux nombreux mariages de descendants de chrétiens que l'Église devrait en principe frapper de nullité :

L'empêchement de consanguinité ainsi que celui d'affinité n'ont pas été non plus respectés et vu la répulsion de nos gens à se marier avec les païens, grand est le nombre de mariages nuls par suite desdits empêchements. Pour corriger toutes ces unions défectueuses ne croyez-vous pas vénéré Monsieur le Supérieur qu'il y aurait lieu de demander à Rome des dispenses in radice ${ }^{75}$.

74. Kunitake Tetsuo 国武喆生 (dir.), op. cit., 1976, p. 20.

75. C'est-à-dire valider rétrospectivement des unions invalides à l'origine ; AMEP, vol. 569, fol. 1679-1688, 19 mai 1866. 
Dans les enquêtes japonaises, on lit souvent que les chrétiens évitent de s'unir avec des non-chrétiens. Lors de la troisième enquête d'Urakami, un officier relate l'histoire d'un homme qui, pour avoir trahi Jésus, aurait reçu une récompense puis se serait pendu ${ }^{76}$. Il ajoute ensuite que les habitants du village « ne se marient pas avec des personnes de la lignée de celui qui s'est pendu 》(緼死等いたし候もの の家筋とは縁組も不致儀に有之 ${ }^{77}$ ). Le Tenchi hajimari no koto rapporte également l'histoire d'un dénommé Jūdasu (Judas) qui aurait connu le même sort ${ }^{78}$. Les chrétiens ne disent pas clairement quelles personnes font partie de la «lignée du pendu », mais dans un autre passage de l'enquête, il est dit qu' ils essaient de se marier à l'intérieur de leur groupe. L'assimilation plus ou moins directe des personnes extérieures au groupe à la figure de Judas montre la défiance des chrétiens cachés envers leur environnement direct. C'est une caractéristique essentielle de ces communautés. La découverte d'Imamura par des catéchistes d'Urakami, deux villages pourtant distants de plus de cent kilomètres, illustre ce fait. Des rumeurs faisant état d'un endroit où les habitants refusaient de se marier avec des « étrangers » en sont à l'origine :

Ensuite, je leur ai demandé comment ils avaient appris notre existence $^{79}$. Ils m'ont dit qu'un des habitants d'Urakami, alors qu' il était à Nishihara dans le district de Mii, [...] avait entendu parler d'Imamura, un village qui semblait être celui de descendants de chrétiens, car ses habitants ne nouaient pas de liens [de mariage] avec les villages extérieurs.

当村の都合如何して承知に相成居候哉の旨相尋候処、 先年浦上村の者御井郡西原村え[...]罷越候砌、今村と申所 切支丹末流の村柄にて外村より縁与等不致由及承罷在候 80

76. Dans le Nouveau Testament, la mort de Judas Iscariote est présentée de différentes manières. Dans l'Évangile selon Matthieu, Judas, pris de remords, se pend, après avoir dénoncé Jésus.

77. TANigawa Ken.ichi 谷川健一 (dir.), op. cit., 1972, p. 834.

78. Hubert Cieslik, Doi Tadao 土井忠生, EBisawa Arimichi 海老沢有道, ŌTsUKA Mitsunobu 大塚光信, op. cit., 1970, p. 398-400 pour le texte en japonais.

79. La personne qui s'exprime est un villageois d'Imamura qui s'entretient avec les catholiques d'Urakami.

80. Kunitake Tetsuo 国武喆生 (dir.), op. cit., 1976, p. 2. 
Les enquêtes menées à Urakami montrent que le village n'était pas entièrement acquis au christianisme. Le grand exil qui a frappé plus de 3000 catholiques du village entre 1868 et 1873 ne touche pas toute la population. Sur huit cents familles, sept cents étaient catholiques en 1867, tandis que les cent autres étaient bouddhistes ou encore crypto-chrétiennes ${ }^{81}$. Quelques années auparavant, lors de la troisième enquête, un officier notait que sur les cinq quartiers du village, quatre étaient exclusivement habités par des «fidèles de l'hétérodoxie 》 (c'est-à-dire les chrétiens), alors que dans le cinquième, il n'y en avait aucun ${ }^{82}$. Ce fait est d'autant plus surprenant que le village, situé à proximité de Nagasaki, participait activement à l'économie régionale. Les villageois empruntaient beaucoup, faisaient du commerce avec la ville et achetaient des terres dans le voisinage ${ }^{83}$. Cependant, ils continuaient de privilégier l'endogamie religieuse ${ }^{84}$.

Cecasn'est toutefois pasl'expression d'une règle absolue. Selon Kojima Yasuko 児 島康子, dans les villages de chrétiens cachés de l'ouest de l'archipel d'Amakusa, les mariages mixtes auraient été assez fréquents. L'historienne base son étude sur des documents locaux issus d'une enquête menée sur ces communautés au début

81. Francisque Marnas, La « Religion de Jésus » (Iaso ja-kyō) ressuscitée au Japon dans la seconde moitié duXIX siècle, t. 1, deuxième édition, Paris, Delhomme \& Briguet, 1931, p. 621-622.

82. TANigawa Ken.ichi 谷川健一 (dir.), op. cit., 1972, p. 841.

83. Toya Toshiyuki 戸谷敏之, Kirishitan nōmin no keizai seikatsu-Hizen-kuni Sonogigun Urakami-Yamazato mura no kenkyū 切支丹農民の経済生活一肥前国彼杵郡 浦上山里村の研究 (L'activité économique des paysans catholiques : étude du village d'Urakami-Yamazato du district Sonogi dans le pays de Hizen), Tōkyō, Itō shoten 伊藤 書店, 1943, p. 154-155; 170-171.

84. Des travaux récents sont venus montrer que dans les campagnes où le développement de l'économie marchande était manifeste, les mariages entre personnes de différents villages, voire de différentes régions, étaient courants. A ce sujet, on peut lire sur le Kansai : KAWAGUCHI Hiroshi 川口洋, «Edo jidai kōki no kinki chihō ni okeru kon.in idō » 江戸時代後期の近畿地方における婚姻移動 (La migration matrimoniale dans la région du Kinki à la fin de l'époque d'Edo), in KuRosu Satomi 黒須里美 (dir.), Rekishi jinkōgaku kara mita kekkon, rikon, saikon 歴史人口学からみた結婚 離婚 再婚 (Les mariages, divorces et remariages étudiés du point de vue de la démographie historique), Kashiwa, Reitaku daigaku shuppan-kai 麗澤大学出版会, 2012, p. 140-170. 
du XIX ${ }^{\mathrm{e}}$ siècle $^{85}$. Les missionnaires français ayant commencé l'évangélisation de la région restent cependant silencieux sur cette particularité.

Quoi qu'il en soit, il apparaît que les chrétiens cachés considéraient généralement les personnes extérieures à leur groupe avec méfiance. Cette méfiance ne s'applique pas seulement aux fidèles des autres religions, mais aussi à d'autres communautés de chrétiens cachés. Les missionnaires font état de crypto-chrétiens qui se regardent avec défiance car leurs pratiques diffèrent :

En vous disant que les anciennes querelles des familles religieuses au Japon ont divisé les chrétiens, je n'exagère rien. Après plus de deux cents ans, il nous en reste des preuves vivantes. Ainsi tel ou tel village parmi ceux qui sont à nous se regardent d'une religion différente parce que les uns gardent l'abstinence le mercredi, vendredi et samedi, tandis que les autres n'observent que les deux derniers jours de la semaine. $\mathrm{Ou}$ bien parce que ceux-ci fêtent tel saint que ceux-là ne reconnaissent point dans leur calendrier. Les uns sont Kirichitan-chous, les autres Paterenchous, ou bien Doghio-chous. Sans doute selon qu' ils descendent des enfants spirituels des Franciscains, Jésuites, Dominicains etc. ${ }^{86}$.

Le rite fonctionne comme une sorte de code, une façon de juger de l'appartenance de quelqu'un au groupe. À Imamura, un villageois s'assure des prières des catholiques d'Urakami, avant d'accepter de leur parler de sa religion ${ }^{87}$. Plus que le contenu doctrinal, c'est le respect formel du rite qui permet de s'identifier au groupe. Un missionnaire français relate dans le premier rapport sur la découverte

85. Kojıma Yasuko 児島康子, «Amakusa kuzure ni okeru kirisuto-kyō no keishō Senrei kara no ichikōsatsu»天草崩れにおけるキリス卜教の継承一洗礼からの 一考察 (La transmission du christianisme observée lors du démantèlement des communautés de chrétiens cachés d'Amakusa : réflexion par rapport à la question du baptême), Kumamoto shigaku 熊本史学, $\mathrm{n}^{\circ}$ 78-79, Kumamoto, Kumamoto daigaku 熊本大学, 2002, p. 25-46.

86. AMEP, vol. 569, fol. 1547-1551, 29 janvier 1866. Pateren vient du portugais padre, le père. Chous est une transcription du terme $s h \bar{u}$ 宗, la religion ou secte dans son sens bouddhique. Le sens de Doghio pose en revanche problème. Peut-être s'agit-il de dōgyō 同行, un terme désignant habituellement un récitant du nenbutsu. Dans les autres documents on ne trouve que les termes pateren et kirishitan.

87. Kunitake Tetsuo 国武喆生 (dir.), op. cit., 1976, p. 2. 
d'Imamura que des femmes du village auraient essayé de scruter les intentions des visiteurs d'Urakami en s'assurant de leur respect du carême :

La veuve leur demande ce qu'ils veulent manger, s'ils pensent prendre des œufs ou de la volaille. Cette question renfermait un aveu. Comprenant que dans ce village les habitants ont déjà commencé leur Carême, afin de dissiper les soupçons et d'éveiller la confiance, ils déclarent qu'ils ne mangeront ni œufs ni volailles. Cette réponse est comprise et elle est accueillie par un rire général ${ }^{88}$.

De ces quelques remarques sur la forte endogamie religieuse, on comprend que la plupart des familles de ces communautés devaient entretenir des liens de sang très étroits. Aujourd'hui encore, dans certains villages catholiques de Kyūshū, beaucoup d'habitants portent les mêmes patronymes. À Imamura, par exemple, l'écrasante majorité du village s'appelle Aoki 青木 ou Hirata 平田 ${ }^{89}$. À Amakusa, dans les villages de chrétiens cachés de l'ouest de l'archipel, l'enquête menée en 1805 montre que près de $99 \%$ des membres de la communauté ont été initiés à cette religion par une personne de leur famille ${ }^{90}$.

Il n'est pas surprenant qu'une communauté clandestine cherche à éviter que ses membres ne se marient avec des «étrangers ». Toutefois, en comparaison à d'autres groupes, l'isolement des chrétiens cachés semble avoir été très important. Par exemple, nous savons que parmi les communautés d'amidistes clandestins de Kyōto et Edo, la diffusion de la pratique religieuse n'était pas seulement basée sur les liens du sang, mais aussi sur des contacts commerciaux ${ }^{91}$.

88. AMEP, vol. 569, fol. 2033-2045, 12 mars 1867.

89. EBISAWA Arimichi 海老沢有道, «Chikugo kuni Mihara gun Imamura no fukkatsu kirishitan 》筑後国御原郡今村の復活キリシタン (La résurrection du catholicisme à Imamura, village du district de Mihara dans le pays de Chikugo), Kirishitan kenkyū キリ シタン研究 (Études sur le catholicisme japonais), vol. 18, Tōkyō, Yoshikawa kōbunkan 吉川弘文館, 1978 , p. 386 .

90. Hirata Masanori 平田正範, Amakusa kakure kirishitan 天草かくれキリシタン (Les chrétiens cachés de l'archipel Amakusa), Ariaki, Santa Maria kan サンタ マリア 館, 2001, p. 186-189.

91. OGURI Junko 小栗純子, op. cit., 1975, p. 89-91. 


\section{CIPANGO}

292 Cahiers d'études japonaises n²1

\section{Une communauté qui se pense en permanence en opposition aux autres religions}

Comment les chrétiens cachés considèrent-ils les personnes extérieures à leur groupe ? On a déjà vu qu'à Urakami, ils les assimilaient, ni plus ni moins, à celui qui a trahi Jésus : Judas. À Imamura, les chrétiens disent qu'ils récitent « uniquement les prières dédiées à Jésus et Marie » car dans leur « religion, on ne vénère pas les kami et bouddhas » (右ゼゾウスマリヤの咒文斗にて、外の神仏等 礼拝不仕宗法に御座候 ${ }^{92}$ ).

La raison est simple. Une femme, qui n'est pas originaire d'Imamura, mais qui est mariée à un chrétien caché de ce village, déclare qu'elle a « appris de [son] mari que l'on ne pouvait pas se sauver avec le nenbutsu, et que celui qui récitait les prières de Jésus et Marie serait sauvé »(念仏にては助り不申候間、ゼゾウソ マリヤ様と唱候はは、助り可申旨 ${ }^{93}$ ). Si le catholicisme a perdu son caractère universel en devenant une religion où le lien familial est quasiment l'unique vecteur de diffusion, la tendance exclusive est restée présente.

Cette approche de la religion se fonde sur une forme de supériorité divine. À Urakami, l'ancien chef religieux du village, Rigorō, aurait fait venir Kichizō pour lui dire que « la divinité principale de leur religion est un bouddha sans égal » ( 宗旨の本尊は無二の仏 $\left.{ }^{94}\right)$. Quand les chrétiens cachés décrivent leur divinité principale (honzon 本尊), qui selon certains est « Sainte Marie », et selon d'autres, «Dieu ${ }^{95}$, ils lui attribuent des caractéristiques extraordinaires qui affirment son excellence. Dans le Tenchi, Dieu, créateur du Ciel et de la Terre, a quarante-deux marques distinctives ( $s \bar{o}$ 相) et deux cents rangs (kurai 位) alors que les bouddhas

92. Kunitake Tetsuo 国武喆生 (dir.), op. cit., 1976, p. 2.

93. Ibid., p. 17. Cet exemple montre qu'il y avait, malgré tout, quelques mariages entre chrétiens et non-chrétiens.

94. Tanigawa Ken.ichi 谷川健一 (dir.), op. cit., 1972, p. 835.

95. Selon Kichizō, Sainte Marie est la divinité principale de leur culte. Le chef ne connaît pas exactement la fonction du Christ et d'un bouddha qu'il appelle Inasshō, une déformation de Saint Ignace. Ibid., p. 833. 
n'en ont que trente-deux ${ }^{96}$. Cette façon de hiérarchiser le divin n'est pas propre aux chrétiens cachés. Les Japonais de l'époque prémoderne attribuent plus ou moins consciemment des rangs aux dieux ${ }^{97}$. L'affirmation d'une supériorité ou de l'efficacité exclusive de sa divinité est également assez commune : des fidèles du Jōdo shinshū se targuaient par exemple de ne pas avoir de sanctuaires shintô dans leur village, expliquant n'attendre que les bienfaits du bouddha unique, Amida ${ }^{98}$.

Un passage du Tenchi est assez significatif de cette idée de supériorité chez les chrétiens cachés. Un dénommé Gakujūran, présenté sous les traits d'un moine d'une des branches de la Terre pure, dialogue avec Jésus et tente de lui expliquer pourquoi il veut garder ses sûtras après sa « conversion » au christianisme :

Gakujūra[n], voyant cela, dit : « Je veux moi aussi devenir Votre élève et Vous respecter comme mon maître. » Mais comme le Seigneur lui dit : « Tous ces livres sont inutiles, il te faut tous les jeter », Gakujūra[n] objecta, en invoquant des arguments tels que : «Il s'agit d'écrits bouddhiques importants, l'Issaikyō 一切経99. Le débat entre les deux maitres n'en finissant pas, le Seigneur finit par dire : «Puisque c'est comme ça, nous allons procéder à un test, et peser ce livre unique et tous ces livres, pour savoir qui est dans le vrai. » Ils firent comme il l'avait ordonné, et lorsqu' ils regardèrent

96. Hubert Cieslik, Doi Tadao 土井忠生, EBISAWA Arimichi 海老沢有道, ŌTsuka Mitsunobu 大塚光信, op. cit., 1970, p. 382. Les sō sont les caractéristiques physiques distinguant les bouddhas du commun (peau lisse et dorée, dents de même longueur, protubérance crânienne, cryptorchidie etc.).

97. FuKAYA Katsumi 深谷克己, «Shi-nō-kō-shō to kinsei mibun-sei»士農工商と近世 身分制 (Le système shi-nō-kō-shō [guerriers, paysans, artisans et marchands] et les statuts sociaux à l'époque prémoderne), in FuKaYA Katsumi 深谷克己, ŌHASHI Yukihiro 大 橋幸泰 (dir.), Edo no hito to mibun - Mibun-ron o hirogeru 江戸の人と身分一身分 論をひろげる (Les gens de l'époque d'Edo et leur statut social : élargissement du débat sur les statuts sociaux), vol. 6, Tōkyō, Yoshikawa kōbunkan 吉川弘文館, 2011, p. 24-26. 98. YASUMARU Yoshio 安丸良夫, Kamigami no Meiji ishin 神々の明治維新 (Le Panthéon shintō durant la restauration de Meiji), Tōkyō, Iwanami shoten 岩波書店, 1979, p. 164-166.

99. Un recueil de tous les textes sacrés du bouddhisme. Voir Christal Whelan, op. cit., 1996, p.102. 
le poids indiqué [par la balance], les nombreux livres étaient légers, contrairement au livre unique, qui était bien plus lourd. Voyant cela, Gakujūra[n] ne put argumenter plus longtemps, et il exprima le souhait de recevoir l'eau sacrée [du baptême ${ }^{100}$.

Celui qui prêchait la vénération du Saint-nom d'Amida (rokuji no myōgō 六字 の名号) est terrassé. Son enseignement est invalidé, alors que celui de Jésus, c'està-dire celui des chrétiens cachés, triomphe. Acculés à la clandestinité, les chrétiens trouvent le réconfort dans l'idée qu'ils sont du côté de la vérité. Mais l'auteur du Tenchi va plus loin. Eux iront au Paradis, et les autres, ceux qui ne sont pas baptisés, tomberont en enfer. Dans un passage qui rappelle le Jugement dernier, Dieu vient choisir les siens :

Ensuite, Deusu [Dieu], qui est tout-puissant, descendra du ciel, il se forgera un chemin [parmi les hommes] et en trois unités de temps, il choisira ceux marqués du sceau et séparera les hommes sur sa droite et sur sa gauche. Et, chose bien triste, les personnes à sa gauche, comme elles n'ont pas reçu le bauchisumō [baptême], tomberont avec les tengu dans l'enfer appelé Benbō [les limbes], et c'est là qu'elles recevront leur sceau. Les personnes qui sont tombées dans ce lieu ne s'élèveront plus jusqu'à la fin des temps. Par contre, les personnes à sa droite, qui ont reçu le bauchisumō, iront toutes au Paraizo [paradis], avec Deusu. Au Paraizo, on jugera leur degré de vertu, d'après lequel on leur attribuera leur rang. Ils sont garantis de devenir des Bouddhas, et de vivre confortablement et comme il leur plaît pour l'éternité ${ }^{101}$.

Avant le retour du clergé catholique, les chrétiens cachés sur lesquels on dispose de documents se pensaient en opposition avec les autres religions. Comme les kakure nenbutsu, ils étaient persuadés d'être les garants d'une certaine forme d'orthodoxie. Cependant, si les premiers se pensaient en rapport à une institution, le Hongan-ji ${ }^{102}$, les seconds rejetaient tout lien avec d'autres communautés

100. Géraldine ANTILLE, op. cit., 2007, p. 58.

101. Ibid., p. 68.

102. OGURI Junko 小栗純子, op. cit., 1975, p. 148-154. 
religieuses. Ils formaient finalement un ensemble de communautés relativement étanches qui pratiquaient dans le secret la religion de leurs ancêtres. L'universalisme de l'Église catholique a disparu pour laisser place à une religiosité toujours exclusive mais dans laquelle l'idée de filiation familiale est fondamentale. Si les autres cultes sont rejetés radicalement, mais secrètement, le salut ne concerne plus toute l'humanité, mais uniquement les chrétiens cachés qui se pensent comme une sorte de peuple élu, car eux détiennent la formule du baptême, des prières et rites particuliers. L'arrivée des missionnaires catholiques va ébranler cette logique.

\section{Le retour du clergé catholique et l'affirmation religieuse des chrétiens}

Le 17 mars 1865, dans l'église d'Ōura 大浦, récemment construite à Nagasaki, un groupe d'une dizaine de villageois d'Urakami vient déclarer sa religion aux missionnaires français. Souvent présenté comme un banal fait de l'histoire diplomatique du Japon de l'époque bakumatsu, le retour du clergé à Kyūshū a eu un impact considérable sur les chrétiens cachés. Une question traverse dès lors toutes les communautés : faut-il considérer les missionnaires comme les véritables dépositaires de la foi et donc rejoindre officiellement l'Église catholique ? L'objet de cette partie est d'étudier l'évolution du regard de ces communautés sur leur foi, notamment pour celles ayant opté pour le catholicisme. Nous pensons que la conversion au catholicisme a été abordée dans une logique de continuité et de fidélité à la foi ancestrale. La préoccupation principale des chrétiens, le salut de l'âme, demeure, mais sa perception est profondément modifiée avec la présence des missionnaires. Le rite ne suffit plus, le respect formel du bouddhisme et le secret sont considérés comme des actes peccamineux par les prêtres. Pour se sauver, les chrétiens doivent désormais se déclarer au grand jour et affirmer leur identité religieuse.

\section{La conversion comme une continuité}

L'histoire est restée célèbre. Cette rencontre entre les chrétiens cachés et les missionnaires a été relatée à diverses reprises. Aux archives des MEP, on trouve de nombreuses lettres rédigées les jours qui l'ont suivie. Il faut dire que jusqu'à cette date, l'évangélisation de l'archipel s'était révélée peu fructueuse pour le clergé 
catholique ${ }^{103}$. Après le 17 mars 1865 , l'objectif des missionnaires est d'établir des liens avec les communautés de chrétiens cachés et de les faire entrer en contact avec l'« orthodoxie » catholique. Pour le clergé, i l y a un véritable travail de conversion à effectuer. Pour les villageois d'Urakami, au contraire, il ne fait au départ pas de doute que la religion des prêtres étrangers est la même que la leur :

Vendredi 17 mars 1865 : Vers midi et $1 / 2$ une troupe de visiteurs se trouvait à la porte de l'Église avec des allures qui dénotaient plus que de la curiosité. Pressé certainement par mon bon ange, je me rends auprès d'eux, leur ouvre l'église et les engage à en faire la visite. J'avais à peine eu le temps de réciter un pater noster que trois femmes de 50 à 60 ans s'agenouillent tout près du lieu où je priais et me disent la main sur la poitrine et à voix basse comme si elles eussent craint que les murs entendissent leurs paroles: « Notre cœur à nous tous qui sommes ici ne diffère point du vôtre. »Vraiment leur dis-je mais d'où êtes-vous donc? « Nous sommes d'Ourakami, dans notre village presque tout le monde nous ressemble. »Soyez béni ô mon Dieu pour tout le bonheur dont mon âme fut inondée à ces paroles ${ }^{104}$ !

Pourquoi les chrétiens cachés sont-ils convaincus « d'avoir le même cœur » que les prêtres alors qu'ils ne se sont pas encore entretenus avec eux ? La réponse tient dans la symbolique catholique présente dans l'église d'Ōura. Les habitants d'Urakami avaient repéré les représentations de la Vierge et le Christ en croix. Peut-être avaient-ils également entendu les prêtres prier en latin.

Très vite, des représentants de communautés de chrétiens cachés accourent à Nagasaki pour s'entretenir avec les prêtres. Ils veulent vérifier l'exactitude de leur propre tradition. Ils demandent aux missionnaires de corriger leurs prières et leur présentent des ouvrages pour s'enquérir de leur validité ${ }^{105}$. Rapidement, ils font

103. Sur l'évangélisation du Japon avant 1865, on peut consulter l'ouvrage un peu désuet mais toujours utile de Francisque Marnas, op. cit., 1931.

104. AMEP, vol. 569, fol. 1268-1275, 22 mars 1865.

105. De nombreux rapports des missionnaires font état de cet empressement des chrétiens à faire vérifier leur tradition religieuse. Par exemple : AMEP, vol. 569, fol. 13671376,18 juillet 1865 . 
le lien entre les missionnaires et les traditions, aussi bien orales qu'écrites, que leur ont léguées leurs ancêtres. À Urakami, Bernard Petitjean est appelé «Pater conhésoro », père confesseur, par les néo-convertis ${ }^{106}$. Il s'agit d'un terme que l'on trouve fréquemment dans le Konchirisan no riyaku こんちりさんのりやく (Les bienfaits de la contrition) ${ }^{107}$. Cet ouvrage rédigé par les jésuites à la fin du $\mathrm{XVI}^{\mathrm{e}}$ siècle, connu dans la plupart des communautés du groupe Sotome-Urakami, explique comment le catholique doit faire pour obtenir le pardon de ses péchés sans passer par l'intermédiaire d'un prêtre ${ }^{108}$. Il avait pour objectif d'aider les fidèles à pallier la faiblesse numérique des missionnaires. Qu'il ait pu être employé pour désigner un prêtre catholique à l'époque Meiji montre bien que pour les villageois des liens existaient entre leur tradition écrite et les prêtres français ${ }^{109}$. En avril 1866, les missionnaires rapportent que leur autorité est reconnue parmi plusieurs de ces communautés ${ }^{110}$.

Cependant, comme l'atteste aujourd'hui encore l'existence de communautés de chrétiens cachés, les prêtres des MEP n'ont pas été reconnus par tous comme étant les successeurs des missionnaires de la première évangélisation ${ }^{111}$. Le clergé français savait que l'argument de la continuité entre le culte légué par les ancêtres et celui de l'Église catholique était essentiel pour gagner des âmes rétives à la conversion. Joseph-Édouard Boehrer (1856-1919) raconte comment il a su obtenir la conversion des habitants de Zenchōdani 善長谷, un village situé dans la péninsule de Nagasaki. Le missionnaire, bien conscient du respect immense de ces villageois pour leurs ancêtres, insiste particulièrement sur ce point :

106. AMEP, vol. 569, fol. 1341-1348, 8 juin 1865.

107. Voir le texte dans Hubert Cieslik, Doi Tadao 土井忠生, EBisAwa Arimichi 海老 沢有道, ŌTSUKA Mitsunobu 大塚光信, op. cit., 1970, p. 361-380.

108. Depuis le quatrième concile de Latran (1215), l'Église catholique préconise que chaque fidèle se confesse au moins une fois l'an. Cependant, au XVI ${ }^{\mathrm{e}}$ et XVII ${ }^{\mathrm{e}}$ siècle, un grand nombre de fidèles japonais ne pouvait le faire faute de prêtres.

109. Hubert Cieslik, Dor Tadao 土井忠生, EBisAWA Arimichi 海老沢有道, ŌTsuka Mitsunobu 大塚光信, op. cit., 1970, p. 364-365.

110. AMEP, vol. 569, fol. 1623-1630, $1^{\text {er }}$ avril 1866.

111. À Amakusa, par exemple, beaucoup de chrétiens cachés estiment que leur religion est différente de celle des missionnaires. Voir AMEP, vol. 569, fol. 3115-3132, 15 août 1884. 
Je leur disais que, puisqu' ils étaient certainement descendants de chrétiens, qu'ils avaient même dans le village une image de la Sainte Vierge, ils ne pouvaient pas ne pas reprendre le chemin qu'avaient suivi leurs ancêtres pendant deux siècles ${ }^{112}$.

Les communautés qui reconnaissent le clergé catholique suivent scrupuleusement ses instructions. Le baptême, rite fondamental pour l'obtention du salut dans les communautés crypto-chrétiennes, en constitue sans doute le meilleur exemple. Les baptiseurs s'empressent de vérifier la formule du baptême auprès des missionnaires. Or, ceux-ci adoptent une position intransigeante. Dans de nombreux cas, ils déclarent que les formules sont invalides, et que, par conséquent, beaucoup des villageois n'ont pu être sauvés. Pour les prêtres français, une formule est invalide quand des mots essentiels manquent, notamment un ou plusieurs éléments de la Trinité. Toutefois, ce jugement sévère sur la tradition des ancêtres ne semble pas avoir suscité de tensions avec les convertis. Au contraire, la majorité des baptiseurs accepte de modifier leur formule et exprime le regret d'avoir sûrement privé du paradis nombre des leurs :

Nous basant sur le grand principe sacramenta propter homines $^{113}$, après avoir rectifié les formules et formé de notre mieux les baptiseurs en activité, nous les avons engagés à donner le saint baptême à tous les enfants en dessous de 7 ans et aux mourants. Pour les mourants nous avons fait promettre aux baptiseurs de leur rappeler les principales vérités de notre sainte foi, de les exciter à la contrition et de leur faire comprendre la nécessité de recevoir le saint baptême à cause des doutes sur le $1^{\text {er }}$ reçu. Aucun de nos chefs baptiseurs n'a été froissé de cette mesure, au contraire presque tous nous ont remercié du fond du cœur et nous ont grandement édifié par la douleur qu'ils nous ont laissé paraître, d'avoir probablement privé du bonheur du Paradis un grand nombre d'âmes. Deux villages parmi ceux que nous croyons baptisés invalidement ayant des chefs

112. AMEP, vol. 569, fol. 2839-2855, 15 août 1883.

113. Les sacrements sont administrés au bénéfice des hommes. 
baptiseurs qui ne sont venus qu'une fois et en qui nous n'avions pas cru reconnaître la confiance voulue n'ont pas encore commencé, nous a-t-on dit, la revalidation, mais partout ailleurs nous savons que nos indications ont été fidèlement suivies ${ }^{114}$.

La réaction des baptiseurs rappelle que la piété des chrétiens cachés n'est pas uniquement liée au respect de la tradition léguée par les ancêtres. Le désir de salut fait accepter aux convertis des changements dans leurs pratiques. La conversion est perçue comme un acte visant à compléter, voire à améliorer, le legs religieux des ancêtres. Il n'y a pas de rupture fondamentale avec le passé. Les prêtres doivent aider les chrétiens à retrouver le culte originel qui, aux yeux des villageois, était pratiqué naguère dans leur communauté.

\section{La conversion comme clivage}

Nous avons vu que les chrétiens cachés considéraient leur religion comme supérieure au bouddhisme. La présence des missionnaires n'atténue pas cette idée. Bien au contraire, elle conduit les convertis à affirmer leur ressenti vis-à-vis des autres religions. En avril 1867, les autorités de Nagasaki débutent les premières enquêtes sur des paysans d'Urakami qui refusent la présence des moines lors des enterrements. Les villageois s'organisent et finissent par demander le droit de pratiquer leur religion sans avoir à adhérer formellement au bouddhisme, car leurs « ancêtres [leur] ont légué un enseignement, celui qu’à part la religion du Maître du Ciel [le catholicisme], aucune autre ne permet le salut dans le monde à venir » (先 祖より申伝の儀有之、天主教の外何宗とても決して後世の助に不相成 候 $\left.{ }^{115}\right)$. L'École véritable de la Terre pure et les autres branches du bouddhisme ne sont nullement aux yeux des catholiques d'Urakami des « enseignements pour le

114. AMEP, vol. 569, fol. 1613-1622, 30 mars 1866.

115. Miyachi Masato 宮地正人, Yasumaru Yoshio 安丸良夫 (dir.), Nihon kindai shiso taikei - Kokka to sh u ukyo 日本近代思想大系一国家と宗教 (Anthologie de textes sur la pensée du Japon moderne : l’État et la religion), vol. 5, Tōkyō, Iwanami shoten 岩 波書店, 1988 , p. 283. 
salut de l'âme »(アリマの助り候教に無御座候 $\left.{ }^{116}\right)$. Ils préfèrent subir toutes sortes de punitions plutôt que d'avoir à y adhérer formellement. On reconnaît là l'influence des missionnaires : l'Église catholique du XIX ${ }^{\mathrm{e}}$ siècle est en lutte permanente contre ce qu'elle considère être l'œuvre du malin, de Satan ${ }^{117}$, incarnée dans l'archipel par le bouddhisme et le shintö̈sme.

Mais peut-on considérer que les catholiques n'ont fait que suivre docilement les instructions des missionnaires ? Assez rapidement, il leur est demandé de détruire les objets de culte shintô-bouddhiques qu'ils possèdent : tablettes funéraires des ancêtres (ihai 位牌) et autels destinés aux divinités shintô (kamidana 神棚). Les convertis opposent peu de résistance à ces instructions. Ils montrent même un certain zèle. À Zenchōdani, une fois la conversion annoncée au prêtre, celui-ci leur demande de détruire les «idoles païennes ». Armés de marteaux, les néo-convertis auraient montré un grand engouement, ravissant le missionnaire bien content de jouer « un mauvais tour au diable » ${ }^{118}$. Avant 1865, ils méprisaient secrètement le bouddhisme et le shintoïsme, car ceux-ci ne permettaient pas d'obtenir le salut. Après cette date, ces religions sont perçues comme des obstacles. L'enseignement des missionnaires donne de la légitimité à la tradition léguée par les ancêtres. Maintenant, les convertis savent pourquoi il ne faut pas vénérer les autres religions. Par exemple, Takaki Sen.emon 高木仙右衛門 explique que les bouddhas et les kami sont de simples êtres humains :

Dieu existait alors que toutes les autres choses n'étaient point. Toutes les choses ont été créées par le Maître du Ciel. Ainsi, il est le Seigneur que l'on doit véritablement vénérer. De plus, comme les bouddhas et kami sont des humains comme nous, il est interdit de leur porter un culte. Si on le fait, le salut dans l'autre monde est impossible. Pour ces raisons, je crois uniquement dans le Maître du Ciel. Même si vous me tuiez, je ne pourrais rendre un culte aux kami et bouddhas.

116. Ibid. Arima est une déformation du latin anima, l'âme.

117. Claude Prudhomme, Missions chrétiennes et colonisation $X V I^{e}-X X^{e}$ siècle, Paris, Éditions du Cerf, 2004, p. 118.

118. AMEP, vol. 570, fol. 2839-2855, 15 août 1883. 


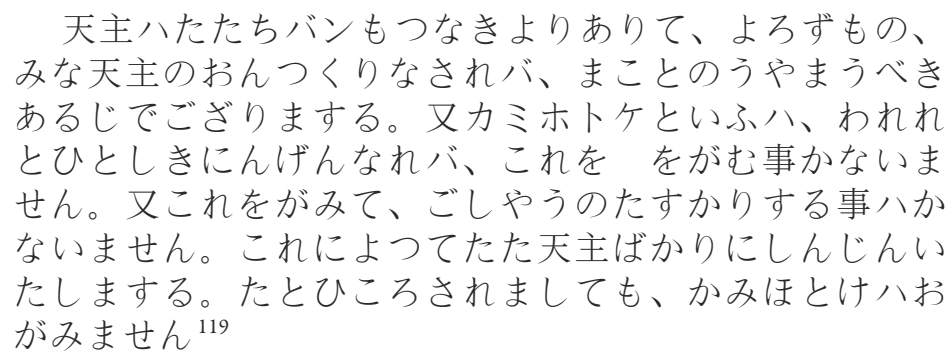

Les convertis ne se contentent pas de suivre les enseignements du clergé. Ils réinterprètent le message biblique à leur façon. Un catholique d'Imamura, arrêté pour avoir tenté de diffuser sa religion dans son village, raconte en quelques lignes la vie du Christ :

Le Tengu a réfléchi : «Si dans 4000 ans, l'homme appelé Jésus Christ naît en ce monde, et prend la succession du labeur divin, je vais encore davantage avoir à souffrir ! » Pour cette raison, 850 années avant le retour du Christ, le Tengu a sollicité le dénommé Shaka [Śākyamuni] originaire d'Inde, afin qu'il répandît la loi bouddhique. La religion chrétienne est, depuis cette époque, ennemie du bouddhisme et du Tengu. [...] À 31 ans, Jésus a commencé à répandre la religion chrétienne. Il avait douze disciples. À cette époque, le bouddhisme était florissant, et [ses fidèles] haïssaient grandement la religion chrétienne.

天狗相考候に、若四千戴の後ゼゼスキリ人とやら生ま れ出、デウスの業を受継なば、我は尚更苦を受ん。依て ゼゼス再来八百五拾年以前、天竺国の釈迦と云ものえ頼 み、仏法を広む。此故に切支丹宗旨と仏法并天狗後来に 至り仇敵なり。[...] ゼゼス三十一歳にして初て切支丹宗門

119. Cette citation est issue des mémoires de Takaki Sen.emon 高木仙右衛門, figure centrale d'Urakami, qui a vécu l'exil entre 1868 et 1873 pour avoir refusé d'apostasier. Le document a été publié par l'une de ses descendantes. TAKAKI Yoshiko 高木慶子, Takaki Sen.emon oboegaki no kenkyū 高木仙右衛門覚書の研究 (Étude des mémoires de Takaki Sen.emon), Tōkyō, Chūō shuppansha 中央出版社, 1993, p. 47-97. Le passage cité se trouve page 69. 
302 Cahiers d'études japonaises n²1

$$
\begin{aligned}
& \text { を弘め、弟子拾弐人有り。此時に当りて仏法盛にして切 } \\
& \text { 支丹の宗旨を悪む事甚し120 }
\end{aligned}
$$

Ce converti a effectué de longs séjours à Nagasaki et à Urakami pour apprendre la doctrine catholique. S'il est aisément compréhensible que le missionnaire en charge de sa formation ait éprouvé quelques difficultés à faire comprendre le milieu historique dans lequel le Christ a vécu et que des distorsions aient pu se produire, il nous semble que cette citation montre d'abord que le converti interprète le contenu biblique au prisme de la rancœur latente qui habitait les chrétiens cachés envers le bouddhisme, avant 1865. Rancœur qui devient vite une obsession. Les nouveaux catholiques, comme s'ils voulaient se faire pardonner d'avoir suivi au moins formellement le bouddhisme par le passé, assimilent tout ce qui touche à cette religion et au shintoïsme à une forme d'impureté. Divers documents produits par les autorités de Nagasaki mentionnent le comportement étrange des convertis à proximité des lieux de culte shintô-bouddhiques. Un rapport de 1870 montre ainsi comment les catholiques d'Urakami font leur possible pour éviter de passer sous des portiques shintô (torii 鳥居) :

Les catholiques [littéralement les « adeptes kirishitan »] ne respectent pas davantage les dieux et bouddhas. Si, par erreur, il leur arrive de les vénérer, il est dit qu'ils recevront de leur religion une lourde punition. Dans le village d'Urakami, il y a un grand sanctuaire [daijingū 大神宮, sanctuaire dédié à Amaterasu]. Si des parents de la religion hétérodoxe surprennent leurs enfants en train de jouer avec insouciance dans l'enceinte du sanctuaire, ils les prennent avec eux, et leur infligent une correction, de sorte qu'ils n'y retournent pas. De même, à un endroit du village, il y a un portique sacré. Des deux côtés, on trouve des habitations qui sont séparées du portique de cinq ou six pouces [un demi-mètre]. Les chrétiens évitent de passer sous celui-ci. Pour ce faire, ils jettent de l'autre côté du portique les fagots de bois qu'ils portent sur le dos, et se faufilent dans l'espace de cinq ou six pouces. Un autre portique sacré est construit sur toute la

120. Kunitake Tetsuo 国武喆生 (dir.), op. cit., 1976, p. 4. 
largeur d'un chemin. Les chrétiens empiètent sur les champs qui se trouvent des deux côtés pour pouvoir circuler.

切支丹宗徒の者は、日本の神仏を更に尊敬せず、若過 て拝し候得ば、深く切支丹宗の罰を請る様と相唱へ、既 に浦上村に大神宮安置有之境内え、異宗の族の小児共無 何心遊び居候処を、其親共見当り、連戻り、再び同所え 相越さず様折檻を加へ、又は往来え鳥居取建有之其左右 人家にて、鳥居と人家とは僅壱尺五、六寸の透有之、切 支丹宗の族は、其鳥居を潜り候事を忌み、依りて背に負 ひ薪等を先に鳥居外に投出し、体は僅の壱尺五、六寸の 透処を横向きになり通り抜け候。或は此外の鳥居有之場 所は往来の幅に取建有之候故、左右の畑地を踏み付け、 往来の様に致し居申候 ${ }^{121}$

L'opposition des convertis au bouddhisme et au shintoïsme s'exprime de temps à autre par la violence physique et verbale. Un autre passage du rapport cité ci-dessus fait état de tensions manifestes entre les convertis et les non-catholiques du village. Les premiers auraient détruit une statue du moine Kūkai 空海 (774-835), gêné les préparatifs des festivités shintô-bouddhiques et attaqué verbalement le bouddhisme en disant que cette religion était « inutile 》 (mueki 無益).

La société villageoise ne se divise pas uniquement entre catholiques et bouddhistes. Si dans leurs discours les catholiques présentent la conversion comme une volonté partagée par tous les descendants de chrétiens ${ }^{122}$, les documents japonais font état de tensions, voire d'attaques physiques contre ceux qui refusent d'embrasser la nouvelle doctrine :

Le $6^{\mathrm{e}}$ mois de l'année du dragon [juillet-août 1868], le catholique Tokuhei, qui vivait du travail du coton et résidait à Nonaka dans le

121. Miyachi Masato 宮地正人, YAsumaru Yoshio 安丸良夫 (dir.), op. cit., 1988, p. 290.

122. Takaki Sen.emon 高木仙右衛門 nie la présence de meneurs dans le village. Pour lui, tout le monde souhaite la diffusion du catholicisme. TAKAKI Yoshiko 高木慶子, op. cit., 1993, p. 53-54. 
quartier de Motobaru à Urakami, a souhaité se repentir de sa faute [c'est-à-dire apostasier] auprès du chef du village. Cependant, les catholiques ont en eu vent, et ont décidé de lui infliger en groupe une bastonnade. Au lieu Uchikoshi, dans le même village, les chrétiens ont attendu le retour de Tokuhei pour l'attraper. C'est en particulier un converti influent, Engorō, qui l'a frappé. Tokuhei est parvenu à s'échapper, mais la situation était telle qu'il n'a pu rentrer chez lui.

去々辰六月頃、浦上村本原郷字野中、綿打渡世の徳 平儀、切支丹宗徒に有之候処、改心致し度旨同村庄屋え 訴出候処、切支丹宗徒の者共、右の趣聞付け、大勢にて 可致打擲と申合、同村打越と申処にて、徳平の帰路を待 請、差押、右徒の内就中円五郎と申者重立及打擲。徳平 は其場を逃去、帰宅もいたし得ず程の義に御座候 123

Mais est-ce nouveau ? Déjà lors de la troisième enquête d'Urakami, un officier notait que « quiconque, maître, parent, fils, frère ainé ou cadet, remettait en cause la religion ou n'y croyait pas, était considéré comme un ennemi du bouddha [= Dieu $] \gg($ 主親子兄弟にても宗体を説破いたし候歟信仰不致ものは仏 敵). Peu importe les difficultés que cette personne devait affronter, elle était abandonnée par le reste de la communauté ${ }^{124}$.

La violence envers les éléments refusant de se plier à la volonté générale était monnaie courante au sein des villages. L'historien Hosaka Satoru 保坂智 a bien montré combien le choix collectif primait sur celui des individus lors des révoltes paysannes (ikki一揆) à l'époque prémoderne. Tout réfractaire à la volonté générale pouvait être sanctionné de différentes manières, notamment par la destruction de ses biens ${ }^{125}$.

Même s'il est difficile d'évaluer l'ampleur du phénomène, on constate que

123. Miyachi Masato 宮地正人, Yasumaru Yoshio 安丸良夫 (dir.), op. cit., 1988, p. 289.

124. Tanigawa Ken.ichi 谷川健一 (dir.), op. cit., 1972, p. 835.

125. HosAKa Satoru 保坂智, Hyakushō ikki to sono sahō 百姓一揆とその作法 (Les révoltes paysannes et leur fonctionnement), Tōkyō, Yoshikawa kōbunkan 吉川弘文館, 2002, p. 150-151. 
dans les villages où le catholicisme triomphe, les familles qui résistent ont souvent été poussées à la conversion ${ }^{126}$. Plusieurs facteurs permettent de comprendre ces comportements. D'abord, le rôle du clergé qui, même s'il n'exhorte pas à la violence, incite les catholiques à transmettre la «Bonne parole » aux autres villageois descendants de chrétiens. Mais l'explication exogène n'est pas pleinement satisfaisante. Avant le retour du clergé catholique, la vie communautaire de ces villages était déjà rythmée par la pratique religieuse. C'est par l'adhésion à une foi particulière que les chrétiens cachés tissaient des liens entre eux. Refuser la conversion, c'était se mettre en dehors de la communauté, et pousser celle-ci à réagir. Dans d'autres cas, on observe des situations inversées. C'est la conversion au catholicisme qui place des villageois en dehors du groupe.

\section{Rejet du monde présent et relativisation du pouvoir en place}

Le changement qui s'opère à partir de 1865 n'est donc pas une rupture radicale avec le passé, ni dans la conscience des néo-catholiques, qui voient dans leur conversion le moyen de parfaire la foi dont ils ont hérité, ni sur le plan des pratiques communautaires.

Le pouvoir des Tokugawa acceptait plus ou moins tacitement l'existence de ces communautés en l'échange d'une soumission formelle aux normes sociales et religieuses. Tant que les chrétiens cachés payaient l'impôt et étaient inscrits dans un temple, le risque qu'ils soient inquiétés par les autorités était faible. Notons toutefois que l'on observe un durcissement de la politique du shogunat vis-à-vis de certains mouvements religieux durant le bakumatsu ${ }^{127}$.

Dans ce contexte, la conversion au catholicisme d'une partie de ces villageois est une atteinte directe à l'une des lois fondamentales du bakufu : la proscription

126. ŌHASHI Yukihiro 大橋幸泰, op. cit., 2001, p. 273-278.

127. Comme en témoigne le traitement infligé aux chefs d'Urakami lors de la troisième enquête (1856-1860) : une dizaine d'entre eux sont morts en prison. Voir KatAoka Yakichi 片岡弥吉, op. cit., 1979, p. 547-548. Dans le domaine de Tajiro, en 1854, de nombreux fidèles de la communauté kakure nenbutsu avaient eux aussi subi des punitions très sévères, en comparaison des sanctions infligées lors des deux précédentes enquêtes au XVIII ${ }^{\mathrm{e}}$ siècle. Voir CHō Tadao 長忠生, op. cit., 1999, p. 64-71. 
du christianisme. En se convertissant et en affichant clairement leur foi, les villageois se placent de jure dans l'illégalité. L'acte même de la conversion est une forme de relativisation du pouvoir, puisque celui-ci signifie que la religion est plus importante que le respect des lois. C'est comme cela que le pouvoir perçoit la chose. Or, ce qui permet l'acte de conversion, c'est aussi bien cette soif de salut qu'une forme de renonciation au monde présent. L'ici-bas est alors perçu comme provisoire alors que ce qui suit après la mort, l'enfer ou le paradis, durera pour l'éternité. On a conservé une supplique adressée aux autorités de Nagasaki, datant d'août 1867, dans laquelle les convertis d'Urakami expriment explicitement leur détachement du présent :

Les prêtres qui se sont récemment installés à Ōura nous enseignent la religion [catholique]. Quiconque la suit de tout son cœur obtient sans l'ombre d'un doute le salut de son âme après la mort. Quelles que soient les épreuves à affronter en ce monde, [il faut savoir que] celles-ci sont temporaires [littéralement « ne dureront que quelques années »]. Dans le monde à venir nous jouirons d'une félicité sans limite. C'est en espérant cela dans la joie que nous vivons aujourd' hui.

此度大浦表へ渡来に相成候教師より教を受け、一心に 其教を守時は、亡魂助無疑出来候儀に付、此世は如何程 艱難仕候而も僅之年数、来世に而果たしなき快楽を請け 候儀に付、唯々夫を相楽しみ今日を相暮し罷在候 128

Cette vision d'un ici-bas temporaire était déjà perceptible dans le Tenchi, à travers la figure de la Vierge Marie. Marie juge « au vu de l'état du monde » qu'il lui sera bien difficile de pouvoir se sauver. Elle reçoit un oracle divin qui lui dicte de garder sa virginité pour pouvoir obtenir rapidement le salut. Dans le même temps, le roi de Roson cherche une épouse ${ }^{129}$. Mis au courant de la grande beauté de Marie, il la fait venir dans son palais. Mais celle-ci refuse les richesses que lui

128. URAKAWA Wasaburō 浦川和三郎, Urakamikirishitan-shi 浦上切支丹史 (Histoire du catholicisme à Urakami), Ōsaka, Zenkoku shobō 全国書房, 1943, p. 150-151.

129. Roson est une déformation de Luçon. 
fait miroiter le roi, et lui rétorque que ces richesses ne sont que de « ce monde », qui «n'est qu'un abri temporaire ». Pour Marie «ce qui compte, c'est le salut dans l'autre monde ${ }^{130}$. Le présent est dévalorisé, méprisé. Il n’est considéré que comme une antichambre du paradis.

Pour les catholiques comme pour les chrétiens cachés, l'objet de vénération est un Dieu créateur de toutes les choses et de tous les êtres. Avant 1865, dans le Tenchi et les enquêtes, la figure d'un dieu créateur est manifeste. Pour Kichizō « parmi les êtres et choses de ce monde, nul ne croît sans recevoir les bienfaits [de Dieu] » ( 世界の諸物其恩愛を不受して成育いたし候もの無之 ${ }^{131}$ ), alors que dans le Tenchi le « Maître du Ciel et de la Terre est le géniteur de tous les êtres et de toutes les choses ${ }^{132}$. Les catholiques, dont les convictions sont confirmées par l'enseignement des missionnaires, affirment encore plus fortement la primauté de Dieu sur tous les êtres. On peut en lire un exemple dans les mémoires de Takaki Sen.emon 高木仙右衛門. Alors que ce dernier est interrogé par les hommes du préfet de Nagasaki, il range le shogun et l'empereur dans la catégorie des créatures de Dieu :

[L'officier dit :] « Toi seul, tu refuses d'écouter ce que dit le shogun. C'est uniquement pour toi que nous organisons cet interrogatoire. Tu nous causes tant de peine. »Ce à quoi j'ai répondu : «On ne peut dire que je refuse d'écouter ce que préconisent l'empereur et le shogun. Avant que le ciel, la terre et toutes les choses n'existent, Dieu était présent. Il a tout créé, l'empereur et le shogun aussi. C'est pourquoi je pense que Dieu leur est supérieur. J'obéirai à tous leurs ordres, sauf ceux qui concernent le bouddhisme et le shintoïsme. Pour tout ce que les lois de Dieu permettent, je suivrai l'empereur et le shogun. »

そのはj一人しやjぐんのいふ事をききいれざるによ
つて、そのはj一人のためにせきをもうけ、これほど御
てかずさすると。それにこたへて、わたくしもうします

130. Géraldine ANTILLE, op. cit., 2007, p. 47-49.

131. Tanigawa Ken.ichi 谷川健一 (dir.), op. cit., 1972, p. 833.

132. Géraldine Antille, op. cit., 2007, p. 41. 


\section{CIPANGO}

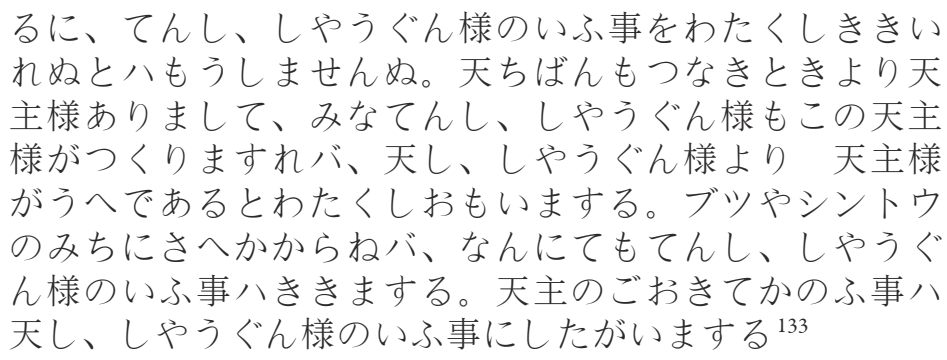

Ici encore, l'attitude de ce converti n'est en aucun cas unique. Le XIX ${ }^{\mathrm{e}}$ siècle voit naître de nombreux mouvements religieux qui relativisent l'autorité temporelle en affirmant l'existence de divinités à l'origine de la création du monde. C'est le cas de nouvelles religions (shinshükyō) comme Tenri-kyō 天理教 ou Konkō-kyō 金 光教. L'historien Yasumaru Yoshio 安丸良夫 a analysé ce phénomène en suggérant que les masses populaires avaient perdu tout espoir de jouir des félicités de ce monde, et qu'elles espéraient un changement radical de la société par le biais d'une force religieuse nouvelle ${ }^{134}$. Pour Ōhashi Yukihiro 大橋幸泰, la conversion au catholicisme des chrétiens cachés relevait de la même logique. Ne faisant plus confiance aux autorités temporelles, ils auraient mis tous leurs espoirs dans la religion chrétienne, et donc dans l'au-delà ${ }^{135}$.

Pourtant, la logique de la conversion des chrétiens cachés nous semble quelque peu différente des espérances de changement que l'on observe dans les nouvelles religions. Les premiers dévalorisent le monde dans lequel ils vivent, alors que les seconds souhaitent ardemment sa transformation. Comme nous avons essayé de le montrer, le désir de salut dans le monde à venir n'a jamais vraiment quitté les communautés de chrétiens cachés. Pour les catholiques reconnaissant l'autorité des missionnaires, la conversion est un moyen plus sûr d'obtenir les bienfaits de l'au-delà. Ainsi, si le contexte social et religieux de l'époque peut expliquer par-

133. TAKAKI Yoshiko 高木慶子, op. cit., 1993, p. 62-63.

134. YASUMARU Yoshio 安丸良夫, Nihon no kindai-ka to minshū shisō 日本の近代化 と民衆思想 (La modernisation du Japon et la pensée populaire), Tōkyō, Heibonsha 平 凡社, 1999, p. 133-136.

135. ŌHASHI Yukihiro 大橋幸泰, op. cit., 2001, p. 173-174. 
tiellement la conversion, nous préférons privilégier les liens de continuité ayant facilité le passage du crypto-christianisme au catholicisme.

\section{Conclusion}

Ainsi, si les chrétiens cachés et catholiques du XIX ${ }^{\mathrm{e}}$ siècle ne représentent qu'une petite minorité à l'échelle de l'archipel nippon, nous pensons qu'ils témoignent d'un monde religieux plus riche et complexe que l'on veut bien le croire. Certaines caractéristiques de leur piété se retrouvent dans d'autres formes de religiosité populaire comme l'amidisme clandestin (le secret, l'organisation, la conviction de détenir la vérité) et les nouvelles religions, notamment du point de vue de la critique qu'ils font du monde dans lequel ils vivent. Mais ce qui rassemble le plus tous ces mouvements, c'est sûrement leur capacité à s'organiser en dehors des circuits établis par le pouvoir, à maintenir des structures parallèles et à accorder une position de primauté à la religion.

Nous n'avons pas voulu aborder la question du point de vue de l'enchevêtrement des croyances qui caractérise leur foi. Il est évident que la religion des chrétiens cachés de la fin de l'époque d'Edo n'était guère « orthodoxe » d'un point de vue catholique. Rappelons-nous que le chef religieux d'Urakami pense que la divinité principale de son culte est Sainte Marie ! L'objet de cette étude n'était pas de juger de l'orthodoxie de telles croyances, mais plutôt de comprendre comment les chrétiens percevaient leur religion. Pour ces chrétiens cachés, mais aussi les premiers convertis, celle-ci était un héritage précieux fait de rites et prières. Ils étaient convaincus que le strict respect de la tradition leur permettrait d'obtenir le salut. L'identité de ces communautés est fortement marquée par leur particularité religieuse. Alors que dans la grande majorité du Japon, le christianisme a fini par disparaître, dans ces villages de Kyūshū, malgré la proscription, le legs des ancêtres s'est transmis au prix d'un comportement discriminant à l'égard de l'extérieur. Le nécessaire secret est devenu avec le temps un pilier de leur foi. Convaincus d'obtenir le salut dans l'au-delà, ils se vengeaient secrètement de ce pouvoir qui les forçait à cohabiter avec les moines.

Les missionnaires n'ont pas radicalement changé les chrétiens cachés. La conversion n'était pas vécue comme une rupture avec le passé, bien au contraire. Rejoindre l'Église catholique c'était parfaire la religion des ancêtres. Une fois que 


\section{CIPANGO}

310 Cahiers d'études japonaises n²1

le lien entre la tradition et l'enseignement des prêtres catholiques était établi, l'engagement des convertis ne pouvait être que total, comme il l'avait été auparavant. Épaulés par les missionnaires, ils ne pouvaient continuer à pratiquer en secret. De passive, leur attitude à l'égard des autres religions est devenue active. L'affirmation religieuse de ces communautés a eu pour conséquence directe d'attiser des tensions avec leur environnement et surtout de provoquer le retour de la répression. Mais qu'importe! Pour ces convertis le monde d'ici-bas n'était que temporaire, et la joie éternelle qui les attendait valait plus que quelques souffrances.

\section{Bibliographie}

Antille Géraldine, Les Chrétiens cachés du Japon : traduction et commentaire des «Commencements du Ciel et de la Terre », Genève, Labor et Fides, 2007, 108 p.

Berthon Jean-Pierre, « Millénarisme, parole et écriture dans le Japon du XIX $^{\text {e }}$ siècle : le cas de la secte Maruyama-kyō », in Josef KYBURZ, François Macé, Charlotte Von Verschuer (dir.), Éloge des sources : reflets du Japon ancien et moderne, Arles, Philippe Picquier, 2004, p. 239-268.

Bouchy Anne-Marie, Tokuhon ascète du nenbutsu : dans le cadre d'une étude sur les religieux errants de l'époque d'Edo, Paris, EPHE v section, Centre d'études sur les religions et traditions populaires du Japon, 1983, $216 \mathrm{p}$.

Boutry Philippe, «Les Mutations des croyances », in Philippe Joutard (dir.), Histoire de la France religieuse, tome 3 : Du roi Très Chrétien à la laïcité républicaine $\mathrm{xviii}^{e}$-xix ${ }^{e}$ siècle, Paris, Seuil, 2001, p. 465-510.

CHō Tadao 長忠生, Naishinjin nenbutsu-kō 内信心念仏考 (Réflexions sur le naishinjin nenbutsu), Fukuoka, Kaichōsha 海鳥社, 1999, 261 p.

Cieslik Hubert (dir.), Kirishitan キリシタン, Tōkyō, Tōkyōdō shuppan 東京 堂出版, 1999, 403+10p. 
Cieslik Hubert, Doi Tadao 土井忠生, Ebisawa Arimichi 海老沢有道, ŌTsUKa Mitsunobu 大塚光信, Kirishitan-sho haiya-sho キリシタン書 排耶書 (Textes catholiques, textes anticatholiques), Nihon shisö-shi taikei 日 本思想史体系 (Anthologie de textes sur la pensée japonaise), vol. 25, Tōkyō, Iwata shoin 岩田書院, 1970, 644+10p.

Duncan Ryuken Williams, The Other Side of Zen: A Social History of Sōtō Zen Buddhism in Tokugawa Japan, Princeton, Princeton University Press, 2005, $241 \mathrm{p}$.

EBISAWA Arimichi 海老沢有道, «Chikugo kuni Mihara gun Imamura no fukkatsu kirishitan 》筑後国御原郡今村の復活キリシタン (La résurrection du catholicisme à Imamura, village du district de Mihara dans le pays de Chikugo), Kirishitan kenkyū キリシタン研究 (Études sur le catholicisme japonais), vol. 18, Tōkyō, Yoshikawa kōbunkan 吉川弘文館, 1978, p. 379-430.

EBISAWA Arimichi 海老沢有道, Kirishitan no dan.atsu to teikō キリシタン の弾圧と抵抗 (Répression et résistance des catholiques japonais), Tōkyō, Yūzankaku shuppan 雄山閣出版, 1981, 244 p.

FukaYa Katsumi 深谷克己, «Shi-nō-kō-shō to kinsei mibun-sei »士農工商

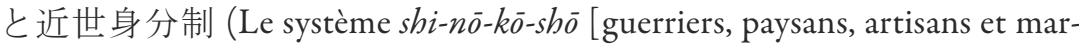
chands] et les statuts sociaux à l'époque prémoderne), in FukaYa Katsumi 深 谷克己, ŌHASHI Yukihiro 大橋幸泰 (dir.), Edo no hito to mibun-Mibun-ron o hirogeru 江戸の人と身分一身分論をひろげる (Les gens de l'époque d'Edo et leur statut social : élargissement du débat sur les statuts sociaux), vol. 6, Tōkyō, Yoshikawa kōbunkan 吉川弘文館, 2011, p. 11-40.

Harootunian Harry, "Late Tokugawa Culture and Play", in Marius B. Jansen (dir.), The Emergence of Meiji Japan, New York, Cambridge University Press, 1995, p. 53-143. 
312 Cahiers d'études japonaises n²1

Hirata Masanori 平田正範, Amakusa kakure kirishitan 天草かくれキリシ夕 ン (Les chrétiens cachés de l'archipel Amakusa), Ariaki, Santa Maria kan サ ンタママリア館, 2001,291 p.

Hosaka Satoru 保坂智, Hyakushō ikki to sono sahō 百姓一揆とその作法 (Les révoltes paysannes et leur fonctionnement), Tōkyō, Yoshikawa kōbunkan 吉 川弘文館, 2002, 204 p.

KamiYa Takehiro 紙谷威広, Kirishitan no shinwa-teki sekai キリシタンの神 話的世界 (L'univers mythologique des chrétiens cachés), Tōkyō, Tōkyōdō shuppan 東京堂出版, 1986, $274 \mathrm{p}$.

KATAOKA Yakichi 片岡弥吉, Nihon kirishitan junkyö-shi 日本キリシタン殉教 史 (Histoire des martyrs catholiques japonais), Tōkyō, Jiji tsūshinsha 時事通 信社, 1979, 696+21 p.

KATAOKA Yakichi 片岡弥吉, Urakami yonban kuzure 浦上四番崩れ (Le quatrième démantèlement du village d'Urakami), Tōkyō, Chikuma shobō 筑摩 書房, 1991, $245 \mathrm{p}$.

KATAOKa Yakichi 片岡弥吉, Oguri Junko 小栗純子, TAMAmuro Fumio 圭 室文雄, Kinsei no chika shinkō 近世の地下信仰 (Les religions clandestines à l'époque prémoderne), Tōkyō, Hyōronsha 評論社, 1974, 328 p.

KAWAGUCHI Hiroshi 川口洋, «Edo jidai kōki no kinki chihō ni okeru kon.in idō» 江戸時代後期の近畿地方における婚姻移動 (La migration matrimoniale dans la région du Kinki à la fin de l'époque d'Edo), in Kurosu Satomi 黒須里美 (dir.), Rekishi jinkōgaku kara mita kekkon, rikon, saikon 歴史人口 学加みた結婚 離婚 再婚 (Les mariages, divorces et remariages étudiés du point de vue de la démographie historique), Kashiwa, Reitaku daigaku shuppan-kai 麗澤大学出版会, 2012, p. 140-170.

Kawamura Shinzō 川村信三, Kirishitan shinto soshiki no tanjō to hen.yō キリ シタン信徒組織の誕生と変容 (La naissance des confréries catholiques au Japon et leur évolution), Tōkyō, Kyōbunkan 教文館, 2003, 477+11 p. 
Kojıma Yasuko 児島康子, « Amakusa kuzure ni okeru kirisuto-kyō no keishō Senrei kara no ichikōsatsu 邓草崩れにおけるキリス卜教の継承一洗 礼からの一考察 (La transmission du christianisme observée lors du démantèlement des communautés de chrétiens cachés d'Amakusa : réflexion par rapport à la question du baptême), Kumamoto shigaku 熊本史学, $n^{\circ}$ 78-79, Kumamoto, Kumamoto daigaku 熊本大学, 2002, p. 25-46.

Kunitake Tetsuo 国武喆生 (dir.), 《 Jashū-mon ikken kuchigaki-chō Mihara-gun Imamura » 邪宗門一件口書帳一御原郡今村 (Transcription du Jashü-mon ikken kuchigaki-chō : Imamura dans le district de Mihara), Kurume kyōdo-shi kenkyū-shi 久留米郷土史研究誌, nº 6, Kurume, Kurume kyōdo-shi kenkyū-kai 久留米郷土史研究会, 1976, p. 1-23.

Lehmann Jean-Pierre, "French Catholic Missionaries in Japan in the Bakumatsu and Early Meiji Periods", Modern Asian Studies, vol. 13, n 3, Cambridge, Cambridge University Press, 1979, p. 377-400.

Marnas Francisque, La «Religion de Jésus» (Iaso ja-kyō) ressuscitée au Japon dans la seconde moitié du XIX $X^{e}$ siècle, t. 1, deuxième édition, Paris, Delhomme \& Briguet, 1931, 689 p.

Miyachi Masato 宮地正人, Yasumaru Yoshio 安丸良夫 (dir.), Nihon kindai shisōtaikei-Kokka to shükyō 日本近代思想大系一国家と宗教 (Anthologie de textes sur la pensée du Japon moderne : l'État et la religion), vol. 5, Tōkyō, Iwanami shoten 岩波書店, 1988,593 p.

MIYAZAKI Kentarō 宮崎賢太郎, Kakure kirishitan no shinkō sekai カクレキリ シタンの信仰世界 (L’univers spirituel des chrétiens cachés), Tōkyō, Tōkyō daigaku shuppankai 東京大学出版会, 1996, 287+16 p.

Murakami Shigeyoshi 村上重良, Kindai Nihon no shükyō 近代日本の宗教 (Le Japon à l'épode moderne et la religion), Tōkyō, Kōdansha 講談社, 1980, $216 \mathrm{p}$. 


\section{CIPANGO}

314 Cahiers d'études japonaises nº 21

Nakajıma Akiko 中島昭子, «Pari gaikoku senkyō-kai shozō Nihon kankei shiryō no kenkyū »パリ外国宣教会所蔵日本関係史料の研究 (Étude des documents des Missions étrangères de Paris relatifs au Japon), Kenkyū kirishitan-gaku研究キリシタン学, $\mathrm{n}^{\circ} 4$, Kirishitan-gaku kenkyū-kai キリシ夕 ン学研究会, 2001, p. 1-63.

Nagura Tetsuzō 奈倉哲三, Bakumatsu minshū bunka ibun - Shinshū monto no shiki 幕末民衆文化異聞－真宗門徒の四季 (Histoire méconnue de la culture populaire durant le bakumatsu : les quatre saisons des fidèles de l'École véritable de la Terre pure), Tōkyō, Yoshikawa kōbunkan 吉川弘文館, 1999, 246 p.

Nogueira Ramos Martin, «Bakumatsu-Meiji shoki no kirishitan minshū shakai no chiiki-teki kōzō ni tsuite no ichikōsatsu »幕末 明治初期の キリシタン民衆社会の地域的構造についての一考察（Réflexion sur l'organisation territoriale des communautés crypto-chrétiennes à l'époque du bakumatsu et au début de l'époque Meiji), Nihonshi kōkyū 日本史放究, $\mathrm{n}^{\circ} 36$, Tōkyō, Nihonshi kōkyūkai 日本史放究会, 2012, p. 23-43.

Nogueira Ramos Martin, « Le Choix de la conversion dans les villages de descendants de chrétiens : le cas d'Imamura dans la province de Chikugo (1867-1879) », in Jean-Michel Butel, Makiko Andro-Ueda (dir.), Japon pluriel 9 : actes du neuvième colloque de la Société française d'études japonaises, Arles, Philippe Picquier, 2014a, p. 375-384.

Nogueira Ramos Martin, Crypto-christianisme et catholicisme dans la société villageoise japonaise $\left(X V I I^{e}-X I X^{e}\right)$, thèse de doctorat de l'université Paris Diderot, sous la direction d'Annick Horiuchi, 2014b, 544+132 p.

OGURI Junko 小栗純子, Myōkōnin to kakure nenbutsu 妙好人とかくれ念仏 (Les pieux pratiquants du nenbutsu et le nenbutsu caché), Tōkyō, Kōdansha 講談社, 1975, 186 p. 
ŌHASHI Yukihiro 大橋幸泰, Kirishitan minshü-shi no kenkyüキリシタン民衆 史の研究 (Études sur l'histoire du christianisme populaire japonais), Tōkyō, Tōkyōdō shuppan 東京堂出版, 2001,342 p.

ŌHASHI Yukihiro 大橋幸泰, « Mura shakai no shūkyō jōsei to itan-teki shūkyō katsudō» 村社会の宗教情勢と異端的宗教活動 (La situation religieuse des sociétés villageoises et les Mouvements religieux hétérodoxes), Rekishi byōron 歴史評論, $\mathrm{n}^{\circ}$ 743, Tōkyō, Azekura shobō 校倉書房, 2012, p. 66-80.

ŌTō Osamu 大藤修, «Shōkeiei, ie, kyōdōtai » 小経営 家 共同体 (Microgestion, maison et communauté), in REKISHI-GAKU KENKYŪ-KAI 歴史学研 究会, NiHON-SHI KENKYŪ-KAI 日本史研究会編 (dir.), Nihon-shi kōzaKinsei shakai-ron 日本史講座一近世社会論 (Cours d'histoire japonaise : sur la société de l'époque prémoderne), vol. 6, Tōkyō, Tōkyō daigaku shuppankai 東京大学出版会, 2005, p. 1-32.

Prudhomme Claude, Missions chrétiennes et colonisation $X V I^{e}-X X^{e}$ siècle, Paris, Éditions du Cerf, 2004, $172 \mathrm{p}$.

Reader Ian, Tanabe George J., Practically Religious: Worldly Benefits and the Common Religion of Japan, Honolulu, University of Hawai'i Press, 1998, $303 \mathrm{p}$.

Roux Pierre-Emmanuel, La Trinité antichrétienne : essai sur la proscription du christianisme en Chine, en Corée et au Japon, thèse de doctorat de l'École des hautes études en sciences sociales, sous la direction de Pierre-Étienne Will, $2013,703 \mathrm{p}$.

Suzue Eiichi 鈴江英一, Kirisuto-kyō kaikin izen - Kirishitan kinsei kösatsu tekkyo no shiryō-ron キリス卜教解禁以前一切支丹禁制高札撤去の史料論 (Avant la levée de l'interdiction contre le christianisme : discussion à partir des sources sur la suppression des placards stipulant l'interdiction de cette religion), Tōkyō, Iwata shoin 岩田書院, 2001, 186 p. 


\section{CIPANGO}

316 Cahiers d'études japonaises n²1

TAKAKI Yoshiko 高木慶子, Takaki Sen.emon oboegaki no kenkyū 高木仙右衛門 覚書の研究 (Étude des mémoires de Takaki Sen.emon), Tōkyō, Chūō shuppansha 中央出版社, 1993, 185 p.

TAKAno Toshihiko 高埜利彦 (dir.), Minkan ni ikiru shükyō-sha 民間に生き る宗教者 (Les religieux qui vivaient parmi le peuple), Tōkyō, Yoshikawa kōbunkan 吉川弘文館, 2000, 272 p.

TAmAmuro Fumio 圭室文雄, Nihon bukkyō-shi-Kinsei 日本仏教史一近世 (Histoire du bouddhisme japonais : l'époque prémoderne), Tōkyō, Yoshikawa kōbunkan 吉川弘文館, 1987, 362+6 p.

TANIGAWA Ken.ichi 谷川健一 (dir.), Nihon shomin seikatsu shiryō shūsei 日本庶 民生活史料集成 (Compilation d'archives sur la vie quotidienne du peuple japonais), vol. 18, Tōkyō, San.ichi shobō 三一書房, 1972, 1024 p.

ToyA Toshiyuki 戸谷敏之, Kirishitan nōmin no keizai seikatsu - Hizen-kuni Sonogi-gun Urakami-Yamazato mura no kenkyū 切支丹農民の経済生活一 肥前国彼杵郡浦上山里村の研究 (L'activité économique des paysans catholiques : étude du village d'Urakami-Yamazato du district Sonogi dans le pays de Hizen), Tōkyō, Itō shoten 伊藤書店, 1943, 256 p.

URAKAWA Wasaburō 浦川和三郎, Urakami kirishitan-shi 浦上切支丹史 (Histoire du catholicisme à Urakami), Ōsaka, Zenkoku shobō 全国書房, $1943,639 \mathrm{p}$.

Watanabe Takashi 渡辺尚志, Hyakushō no chikara - Edo jidai kara mieru Nibon 百姓の力一江戸時代から見える日本 (Le pouvoir des paysans : le Japon au prisme de l'époque d'Edo), Tōkyō, Kashiwa shobō 柏書房, 2008, $243 \mathrm{p}$.

Whelan Christal, The Beginning of Heaven and Earth: The Sacred Book of Japan's Hidden Christians, Honolulu, University of Hawai' i Press, 1996, 135 p. 
Yasumaru Yoshio 安丸良夫, Kamigami no Meiji ishin 神々の明治維新 (Le Panthéon shintô durant la restauration de Meiji), Tōkyō, Iwanami shoten 岩 波書店, $1979,215 \mathrm{p}$.

Yasumaru Yoshio 安丸良夫, Nihon no kindai-ka to minshū shisō 日本の近代 化と民衆思想 (La modernisation du Japon et la Pensée populaire), Tōkyō, Heibonsha 平凡社, 1999, 488 p.

\section{Archives des Missions étrangères de Paris (AMEP)}

Vol. 569 : Japon 1839-1872

Vol. 570 : Japon 1873-1876

Vol. 570 : Japon méridional et Nagasaki

Résumé: Alors qu'il existe une vaste littérature scientifique sur le « siècle chrétien » du Japon $\left(\mathrm{XVI}^{\mathrm{e}}-\mathrm{XVII}^{\mathrm{e}}\right)$ ou sur les communautés crypto-chrétiennes encore en activité aujourd'hui, les chrétiens cachés et catholiques du XIX ${ }^{e}$ siècle n'ont pratiquement pas attiré l'attention des chercheurs. En prenant pour exemple des villages abritant ces populations à Kyūshū, cet article montre le poids de la religion dans le quotidien, l'organisation sociale et sur la perception de l'autre. En 1865, l'Église catholique, de retour au Japon, établit des contacts avec ces communautés ; un mouvement de conversion débute. Pour ces villageois, rejoindre le catholicisme est perçu dans la continuité du culte des ancêtres. Cependant, si auparavant ils gardaient secrètement leur religion, devenus catholiques, ils affirment leur identité et entrent en conflit avec leur environnement direct.

Mots-clés : catholicisme, chrétiens cachés, conversion, société villageoise, identité, clandestinité religieuse

Abstract: Whereas many studies have been written on Japan's "Christian Century" (16th and 17th centuries) and the last hidden Christian communities still active today, the hidden Christian/Catholic villages of the nineteenth century remain 


\section{CIPANGO}

318 Cahiers d'études japonaises $n^{\circ} 21$

virtually uninvestigated. My aim is to show how religion influences the social organization of these villages, their contacts with the external world, and their perception of others. In 1865 the Catholic Church, which had returned to Japan, made contact with these communities, triggering a wave of conversions. For these peasants, embracing the Catholic religion meant continuing the cult of their Ancestors. However, whereas previously they would keep their faith a secret, they now assert their identity as Catholics and clash with their direct environment.

Keywords: Catholicism, Hidden Christians, Conversion, Village Society, Identity, Religious Secrecy

キーワード：カトリック, 潜伏キリシタン, 改宗, 村落社会, アイデン ティティー,地下信仰 